Effect of AC electric field on flame spread in electrical wire: variation in polyethylene insulation thickness and di-electrophoresis phenomenon

Sun Ho Park ${ }^{1}$, Seung Jae Lim², Min Suk Cha ${ }^{3 *}$, Jeong Park ${ }^{1 *}$, Suk Ho Chung ${ }^{3}$

${ }^{1}$ Department of Mechanical Engineering, Pukyong National University, Busan, Korea

${ }^{2}$ Dept. of Mechanical Engineering, University of South Carolina, Columbia, USA

${ }^{3}$ King Abdullah University of Science and Technology (KAUST), Physical Science and Engineering Division (PSE)/Clean Combustion Research Center (CCRC), Thuwal, Saudi Arabia 


\title{
Effect of AC electric field on flame spread in electrical wire: variation in polyethylene insulation thickness and di-electrophoresis phenomenon
}

\author{
Sun Ho Park ${ }^{1}$, Seung Jae Lim², Min Suk Cha ${ }^{3 *}$, Jeong Park ${ }^{1 *}$, Suk Ho Chung ${ }^{3}$ \\ ${ }^{1}$ Department of Mechanical Engineering, Pukyong National University, Busan, Korea \\ ${ }^{2}$ Dept. of Mechanical Engineering, University of South Carolina, Columbia, USA \\ ${ }^{3}$ King Abdullah University of Science and Technology (KAUST), Physical Science and \\ Engineering Division (PSE)/Clean Combustion Research Center (CCRC), Thuwal, Saudi \\ Arabia
}

\begin{abstract}
The effect of AC electric field on flame spread over polyethylene (PE)-insulated electrical wire was experimentally investigated by varying the applied $\mathrm{AC}$ voltage $\left(V_{\mathrm{AC}}\right)$ and frequency $\left(f_{\mathrm{AC}}\right)$ with special attention to the effect of the thickness of the PE insulation material $\left(T_{\text {ins }}\right)$. The diameter of the Ni-Cr wire was $0.5 \mathrm{~mm}$ and $T_{\text {ins }}$ was $0.15,0.3$, and $0.5 \mathrm{~mm}$, yielding outer diameters $\left(D_{\text {out }}\right)$ of $0.8,1.1$, and $1.5 \mathrm{~mm}$, respectively. For the baseline cases with no electric field, the flame spread rate (FSR) (flame size) decreased (increased) with insulation thickness. Both FSR and flame size were appreciably influenced by applied AC electric fields. The FSR behaviors under applied electric fields could be classified into three sub-regimes as AC frequency increased: regime I exhibited a decreasing FSR as AC frequency increased, regime II exhibited an increasing FSR, and regime III again exhibited a decreasing FSR. Molten PE dripped from the wire (resulting in mass loss); exhibited di-electrophoresis (some molten PE moved from the main molten zone toward the burnt wire, forming globules in the process); and developed electrosprays (ejection of small droplets from the molten PE surface). For $D_{\text {out }}=0.8$ $\mathrm{mm}$, the FSR behavior was similar to that of the flame width, such that the behavior could be explained by the thermal balance mechanism. When a low voltage and high frequency were applied to wires with $D_{\text {out }}=1.1$ and $1.5 \mathrm{~mm}$, molten PE droplets detached and moved to the burnt wires continuously (although sometimes intermittently) from the main body of molten PE; the FSR behavior thus deviated from that of regime I. Droplet detachment was attributable to a di-electrophoresis. The distance moved correlated well with the difference in electric field intensities of burnt and unburned wires. Appreciable dripping of molten PE occurred at high voltages and moderate frequencies in regime II. When the frequency was excessive, flame extinction occurred via two routes: appreciable reduction of flame size when $D_{\text {out }}=0.8 \mathrm{~mm}$ in regime I and appreciable fuel mass loss via dripping of molten PE during flame spread when $D_{\text {out }}=0.8$ and $1.1 \mathrm{~mm}$ in regime III. These extinction frequencies correlated well with $V_{\mathrm{AC}} / D_{\text {out. }}$ When high voltage and frequency were applied in the $D_{\text {out }}=1.5 \mathrm{~mm}$ case, droplets detached and moved to the burnt wire via di-electrophoresis; subsequently a series of fine droplets ejected from the surface via electrospraying, while the molten PE region grew and subsequently dripped. In such cases, flame extinction did not occur because di-electrophoresis increased the flame width and thereby the FSR over the experimental ranges of $V_{\mathrm{AC}}$ and $f_{\mathrm{AC}}$.
\end{abstract}

Keywords: Flame spread; Electrical wire; AC electric field; Di-electrophoresis; Electrospray; 


\section{Introduction}

Electrical wire fires caused by unexpected arcing, short circuits, and/or overheating may ignite combustible insulation material, posing serious safety hazards. In particular, in a closed environment such as a manned spacecraft or a submarine with no avenue of escape, electrical wire fires may cause fatalities [1-4] (e.g., the Apollo 1 and Mir space station accidents); fires must be actively suppressed [5]. In an aircraft, electrical wire fires are also serious (e.g., the Swissair accident was caused by an arc-initiated fire) [6]. Electrical wire fires are one of the main causes of building, household, and industrial fires [7-9]. The extensive experiments of the CAROLFIRE test series were conducted using electrical wires and/or electrical cables to seek to control fires associated with nuclear accidents [10-12].

The behaviors of wire fires (e.g., electrical wires ignited by external heat [13-15]), the flammable limits [16], and flame spread rates over electrical wires [17-24], have been studied in terms of various experimental parameters such as insulation material and thickness, external heating, ambient air flow and pressure, and gravity (normal- and micro-gravity). Additionally, fire safety issues in space have been extensively investigated [5, 25-28].

Electrical wires for use in spacecraft must meet the NASA fire safety codes [29, 30]; upward flame spread over an inclined wire under ambient conditions. These codes, however, do not consider the effects of electric fields applied to a wire. When an electrical circuit is disconnected by unexpected arcing, electrical shorts, and/or overheating, the electrical system becomes an open circuit. However, an electrical potential (or voltage) can still be applied in the system. Once an insulation material is caught on fire, the wire flame is influenced by the electric field in a single electrode configuration (i.e., an open circuit) [2]. In such a case, charged particles generated via chemi-ionization and subsequent ion chemistry in the reaction zone of a spreading flame can be influenced by the electric field via the Lorentz force [31]. 
Studies of the effects of AC electric fields on flame spread over electrical wires are limited [1-3]. The results for wires with polyethylene (PE) insulation were complicated and associated with the behavior of molten PE on wires that were either horizontal [1, 2] and/or inclined [3]. The phenomena included: internal circulation of molten PE caused by Marangoni convection by the temperature difference between burnt and unburned sides of wire [2]; PE vapor jet ejection from the surface of a molten PE insulator, caused by boiling on the wire surface and subsequent bursting; dripping of molten globular PE for downward-spreading flames, leading to flame extinction if dripping was pronounced; and an electrospray phenomenon in upwardspreading flames (ejection of a series of multiple small droplets from the main molten PE) [3].

These phenomena were observed over the AC frequency range $10-1,000 \mathrm{~Hz}$, which is of practical importance, as utility power generation is $50-60 \mathrm{~Hz}$ and aircraft power is typically $400 \mathrm{~Hz}$, although it can range over $360-720 \mathrm{~Hz}$ (even over $1 \mathrm{kHz}$ at full throttle) [32]. Spacecraft DC power supplies are designed to use voltages of $\sim 5 \mathrm{kV}$ to power analyzers, spectroscopes, and cameras, and can be even higher than $15 \mathrm{kV}$ for spaceborne radar systems making ground observations [33]. Also, problems may arise when outdoor transmission lines carrying power at several hundred kilovolts crossing forested and agricultural areas $[34,35]$.

Here, we report the effects of PE-insulation thickness on flame spread behavior over electrical wires under the influence of applied AC electric fields. The thickness of the insulation material appreciably influences the burning behavior of wire even in the absence of an electric field, via the heat capacity of the insulator (reflected in the evaporation rate) and flame size, influencing the flame spread rate (FSR) $[8,12]$. PE-insulated electrical wires with $\mathrm{Ni}$-Cr core were selected because they have been extensively studied as baseline test cases allowing a fundamental understanding of flame spread behavior in electrical wires [1-3, 13, 15, 17-23]. Note that there are various parameters affecting flame spread rate in electrical wire fires such 
as core materials (such as copper by changing heat conduction through wire $[14,16,17,22]$ ) and insulation material/fire resistance additives. The various interesting phenomena mentioned above will be reported, along with a new observation of a di-electrophoresis phenomenon, emphasizing the important effects of the dynamic behaviors of molten PE on the flame spread rate.

\section{Surrounding mesh (Acetal resin)}

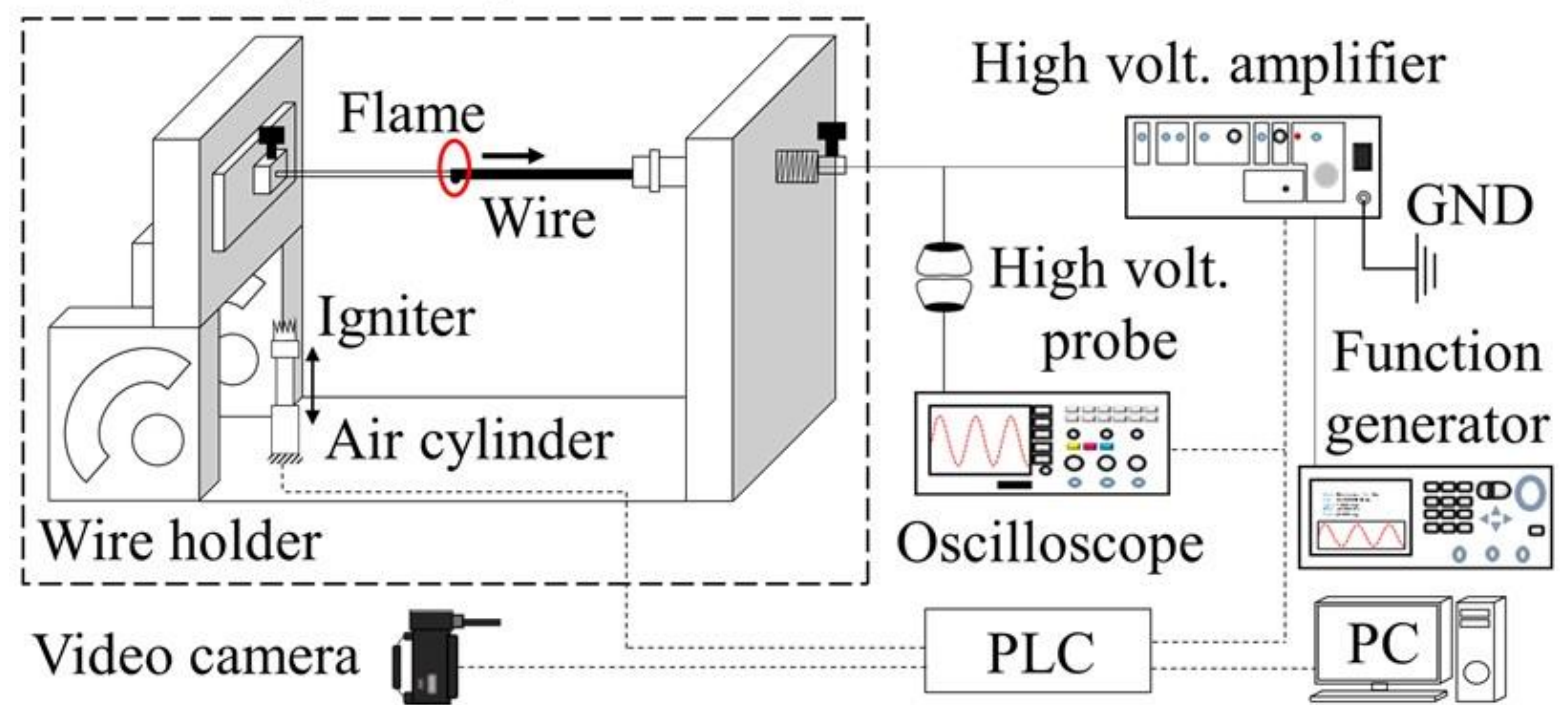

Figure 1. Schematic illustration of experimental setup.

\section{Experiment}

The apparatus consisted of an electrical wire and wire-holder, an AC power supply, and a visualization setup, as schematically shown in Fig. 1. PE-insulated electrical wires (made of nichrome $(\mathrm{NiCr})$ of core diameter $D_{\mathrm{c}}=0.5 \mathrm{~mm}$ ) were used with the insulation thicknesses $T_{\text {ins }}$ $=0.15,0.3$, and $0.5 \mathrm{~mm}$, yielding the outer diameters $\left(D_{\text {out }}\right)$ of $0.8,1.1$, and $1.5 \mathrm{~mm}$, respectively. The lengths of the sample wires were $400 \mathrm{~mm}$ with test section lengths of $247 \mathrm{~mm}$ after excluding the portions connected to the wire-holder. The wire length available for steady flame spread was $167 \mathrm{~mm}$, excluding the initial $70 \mathrm{~mm}$ from the igniter (because of the ignition 
transient) and the final $10 \mathrm{~mm}$ (because of interaction with wire-holder). The wire was installed horizontally on a wire holder. One end of the wire was attached to a fixture and the other end to a spring to prevent any bending caused by thermal expansion during flame spread. The wire holder was made of non-conductive acetal resin and the test section is surrounded by acetal mesh screens $(90 \times 90 \times 90 \mathrm{~cm})$ to prevent outside disturbance. A time-varying AC electric field could induce a magnetic field, according to the Maxwell equations. However, the influence on the Lorenz force by induced magnetic field is expected to be very small as compared with that by applied electric field [36, 37].

A flame was initiated by a hot-wire igniter $(1 \mathrm{~mm}$ in diameter, $\mathrm{Pt} / \mathrm{Rh} 13 \%)$ placed on an air cylinder. To minimize the interaction between the ignition system and the applied AC electric field, the igniter was moved away from the wire after ignition. A programmable logic controller (PLC) was used to control the time sequence of the experiment. Details of the experimental procedure have been reported previously [1-3]. A video camera was triggered to capture images of flame spread, and the recorded images were analyzed using a Matlab-based code. The FSR and flame size were determined in seven trials and the maximum and minimum variations are presented as error bars. Close-up images were obtained using backlight illumination to visualize the dynamic behavior of molten PE.

An AC power supply (Trek, 10/10B-FG) was used to apply an electric field to the wire. The $\mathrm{AC}$ frequency $\left(f_{\mathrm{AC}}\right)$ and voltage $\left(V_{\mathrm{AC}}\right)$ were varied over the ranges of $10-1,000 \mathrm{~Hz}$ and $0-5 \mathrm{kV}$, respectively, and monitored using an oscilloscope fitted with a 1,000:1 probe (Tektronix, 6015A). One end of the wire was connected directly to the high-voltage terminal of the AC power supply and the other terminal of the power supply was connected to the building ground, creating an open circuit. The induced electric field can be assumed to have been distributed axisymmetrically between the wire electrode and an imaginary infinite ground [1-3], as the 
ratio of wire length to wire diameter was very large.

\section{Results and Discussion}

\subsection{Overall features of flame spread}

Instantaneous images of spreading flames when $\mathrm{AC}$ frequencies were applied to wires with various outer diameters at $V_{\mathrm{AC}}=4 \mathrm{kV}$ are shown in Fig. 2 when the flames were in the range $109 \leq X \leq 128 \mathrm{~mm}$, where $X$ is the distance from the ignition point. The results show that flame size, shape, and inclination angle were appreciably modified by the AC electric field and the flame size generally increased as wire outer diameter increased. The flames for the baseline cases with no electric field were nearly vertical for wires of all diameters, because of the buoyancy effect. 


\section{$4 \mathrm{kV}$ Baseline $\quad 10 \mathrm{~Hz} \quad 60 \mathrm{~Hz} \quad 200 \mathrm{~Hz} \quad 600 \mathrm{~Hz} \quad 1 \mathrm{kHz}$}

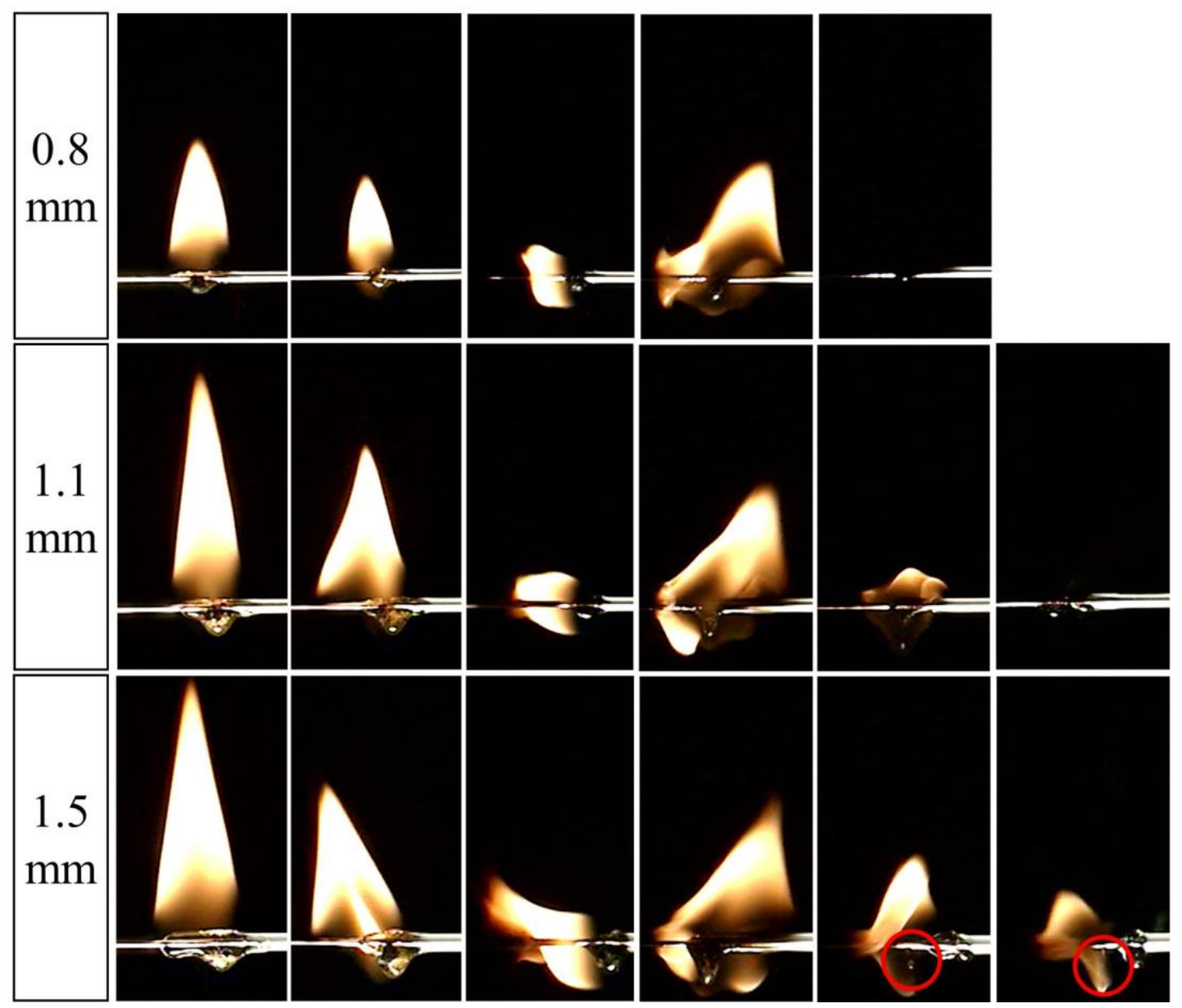

Figure 2. Images of spreading flames with $\mathrm{AC}$ frequency at $V_{\mathrm{AC}}=4 \mathrm{kV}$ for wires of several outer diameters.

For $D_{\text {out }}=0.8 \mathrm{~mm}$, the flame shape behaviors were similar to those observed previously for wires of the same diameter [1]. The flame leaned toward the burnt side at 10 and $60 \mathrm{~Hz}$ and became nearly vertical at $200 \mathrm{~Hz}$. As the AC frequency further increased, the flame was extinguished at $f_{\mathrm{AC}}>200 \mathrm{~Hz}$. Such flame-leaning behavior has been attributed to electric field intensity [1], which is larger in burnt (bare) wire than in unburned wire because the latter retains insulation material. The flame height decreased as AC frequency increased up to $60 \mathrm{~Hz}$, and then increased as the frequency rose further to $200 \mathrm{~Hz}$; the flame width changed little to $60 \mathrm{~Hz}$ and then increased appreciably for $f_{\mathrm{AC}}>60 \mathrm{~Hz}$, such that the flame covered both the burnt and unburned sides of the wire was extended in the horizontal direction. The frequency of $60 \mathrm{~Hz}$ 
seems to be a turning point in the flame responses. This can be partially understood based on the collision response time for the ionic wind to occur [38-41]. Since the concentrations of charged particles are very low, multiple collisions are required to effectively transfer sufficient momentum to neutral molecules to generate an ionic wind. However, details on this turning point behavior requires a future study.

For wires with $D_{\text {out }}=1.1$ and $1.5 \mathrm{~mm}$, the flame behaviors (leaning direction and flame size) up to $200 \mathrm{~Hz}$ were similar to those for the wire with $D_{\text {out }}=0.8 \mathrm{~mm}$. The flame sizes (height and width) again decreased appreciably for $f_{\mathrm{AC}}>200 \mathrm{~Hz}$. The flames were extinguished at $f_{\mathrm{AC}}$ $>600 \mathrm{~Hz}$ for wire of $D_{\text {out }}=1.1 \mathrm{~mm}$ but were sustained even at $1.0 \mathrm{kHz}$ for wire with $D_{\text {out }}=1.5$ $\mathrm{mm}$.

Soot deposition on molten PE and on the wire surface for the baseline case (no electric field) was negligible, as shown in Fig. 2, where molten PE is transparent. As the applied AC frequency increased, molten PE and the surface of the burnt wire became darker because of soot deposition caused by thermophoretic and electrophoretic forces. Near $f_{\mathrm{AC}}=200 \mathrm{~Hz}$ for all wire diameters, dripping of molten PE occurred, similar to that observed previously for a wire with $D_{\text {out }}=0.8 \mathrm{~mm}[1,2]$. Such dripping is attributable to an imbalance between the downward gravitational force on molten PE and surface tension. The soot deposition mentioned above may affect the various heat transfer modes (conduction, convection, and radiation), and may increase the wire surface temperature, in turn affecting PE melting and potentially the temperature, resulting in reduction of the surface tension of molten PE, leading to dripping. As $f_{\mathrm{AC}}$ increased further to over $200 \mathrm{~Hz}$, flame extinction was attributable to a lack of molten PE (caused by excessive dripping) when the wire $D_{\text {out }}$ was $0.8 \mathrm{~mm}$, as observed previously [1]. However, for the wire of $D_{\text {out }}=1.1 \mathrm{~mm}$, the flame was sustained up to $f_{\mathrm{AC}}=600 \mathrm{~Hz}$ even though the dripping frequency of molten PE increased appreciably. This point will be further 
discussed later.
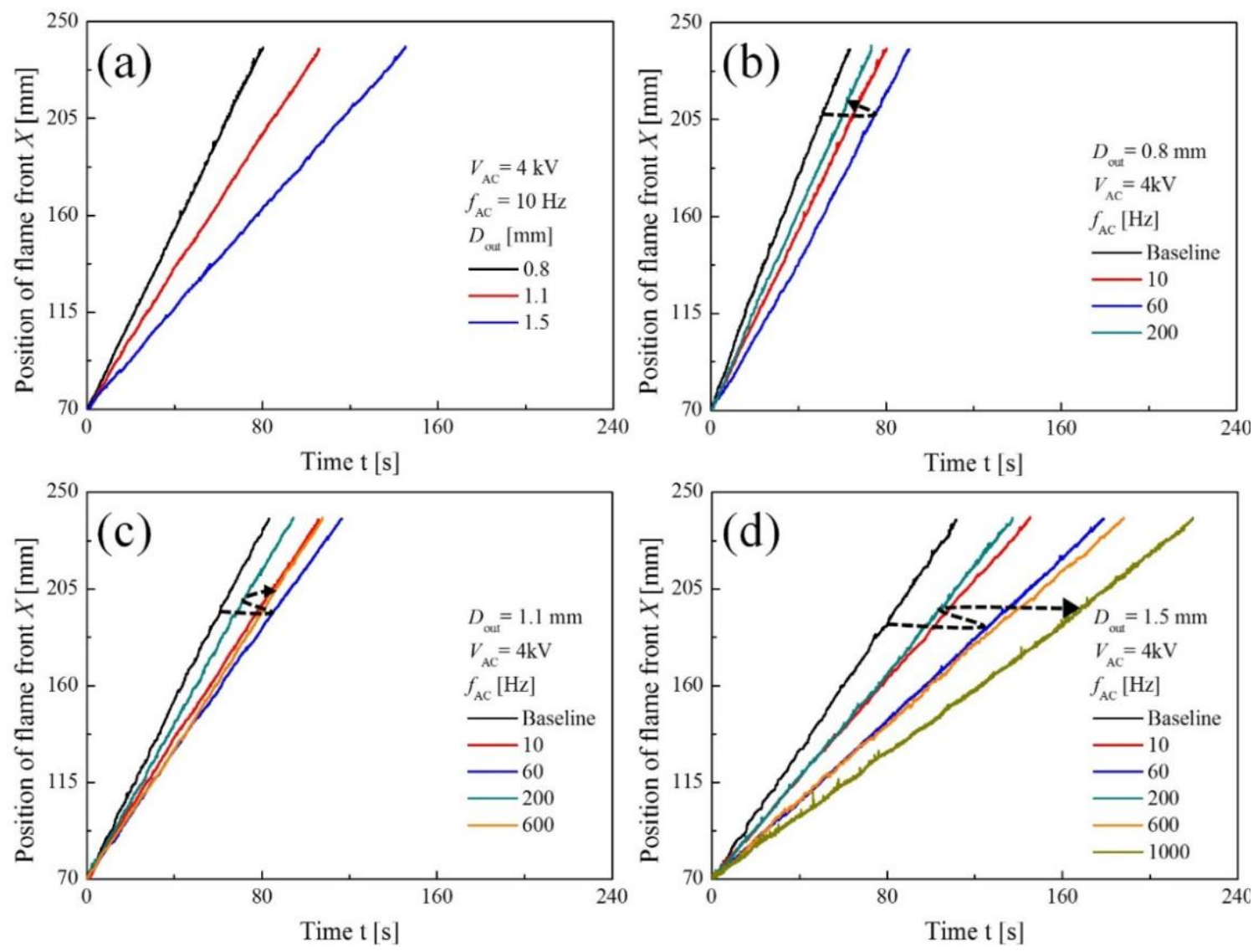

Figure 3. Flame front positions over time for wires of different outer diameters at $V_{\mathrm{AC}}=4 \mathrm{kV}$ and $f_{\mathrm{AC}}=10 \mathrm{~Hz}(\mathrm{a})$; and at various frequencies for wires of $D_{\text {out }}=0.8(\mathrm{~b}), 1.1$ (c), and $1.5 \mathrm{~mm}$ (d) and $V_{\mathrm{AC}}=4 \mathrm{kV}$ (the baseline cases with no electric field are also shown).

For the wire of $D_{\text {out }}=1.5 \mathrm{~mm}$ (marked with red circles for $f_{\mathrm{AC}}=600$ and $1,000 \mathrm{~Hz}$ in Fig. 2), some molten PE (droplet-shaped) became detached from the main bulk of molten PE and moved toward the burnt wire, increasing the surface area of the molten PE. This phenomenon has not been observed previously in wire fire studies and can be attributed to a dielectrophoresis phenomenon, which will be discussed in detail later. Subsequently, a series of fine droplets are ejected from the detached molten PE; this is the electrospray phenomenon [3], which will also be explained in more detail later.

Figure 3 shows the flame front positions $(X)$ with time $(t)$ for wires of various diameters at different $\mathrm{AC}$ frequencies with $V_{\mathrm{AC}}=4 \mathrm{kV}$. The time zero was defined as the time when a 
spreading flame attained $X=70 \mathrm{~mm}$ from the ignition point; we thereby excluded any effect of the ignition transient. The flame front position was determined as follows [2, 3]. The image of a spreading flame was converted to a monochromatic image and then enhanced using the IMADJUST function in Matlab ${ }^{\circledR}$. A threshold value was set from the histogram of the image, and the image was subsequently converted to a binary system (with a center intensity of 127 from the monochromatic intensity range $0-255)$. Since the wire was fixed in space, a reference line for the wire surface could be determined a priori in flame images. A flame front position can then be identified by the cross-point between the reference line and the flame front edge at the unburned wire side. A selection of specified intensity (here 127) minimally affects flame spread rate determination. Note that although there is a quenching zone near the unburned wire, a side view image of flame shows a luminous flame front touching the unburned wire because of a three-dimensional nature of flame edge.

The results showed that the flame front position was generally linear over time even when dripping and the electrospray were in play, indicating that, overall burning was steady. The rate of change in the flame front position was influenced by the wire diameter and the AC electric field. For $V_{\mathrm{AC}}=4 \mathrm{kV}$ and $f_{\mathrm{AC}}=10 \mathrm{~Hz}$ (a), the flame front position increased more slowly as $D_{\text {out }}$ increased. With varying AC electric fields $(\mathrm{b}-\mathrm{d})$, the flame front position increased more slowly than that of the baseline case for wires of all tested diameters. As marked with the dotted arrows, the flame front position increased slowly as $f_{\mathrm{AC}}$ rose to $60 \mathrm{~Hz}$ and this became faster as $f_{\mathrm{AC}}$ continued to rise to $200 \mathrm{~Hz}$ for wires of all diameters, becoming slower once more as the frequency rose further for wires of $D_{\text {out }}=1.1$ and $1.5 \mathrm{~mm}$. Thus, flame behavior was nonmonotonic as AC frequency increased.

\subsection{Flame spread rate with AC electric field}


The rate of change in the flame front position $(X)$ with time $(t)$ was reasonably linear, as shown in Fig. 3, such that the overall FSR $S_{\mathrm{w}}$ could be determined from $S_{\mathrm{w}}=\mathrm{d} X / \mathrm{d} t$. The effect of wire diameter is shown in Fig. 3 a for $V_{\mathrm{AC}}=4 \mathrm{kV}$ and $f_{\mathrm{AC}}=10 \mathrm{~Hz}$; the $S_{\mathrm{w}}$ values were $=2.09$, 1.57 , and $1.15 \mathrm{~mm} / \mathrm{s}$ for $D_{\text {out }}=0.8,1.1$, and $1.5 \mathrm{~mm}$, respectively, thus decreasing as $D_{\text {out }}$ increased. Note that the mass burning rates given by $\rho_{\mathrm{PE}} \times\left\{\pi\left(D_{\text {out }^{2}}{ }^{2}-D_{\mathrm{c}}{ }^{2}\right) / 4\right\} \times S_{\mathrm{w}}$ were $5.62 \times 10^{-4}$, $1.04 \times 10^{-3}$, and $1.59 \times 10^{-3} \mathrm{~g} / \mathrm{s}$, respectively, thus increasing with $D_{\text {out. Here, } \rho \text { PE }}$ is the molten PE density of $8.78 \times 10^{-4} \mathrm{~g} / \mathrm{mm}^{3}$.

The FSR data are shown in Fig. 4 as a function of the AC frequency at several voltages for all tested wires. The FSR for the baseline case with no electric field, $S_{\mathrm{w}, 0}$, is plotted (dotted lines) for reference. For all tested wire diameters, the FSRs under applied electric fields were smaller than the baseline values except for that at $f_{\mathrm{AC}}=1,000 \mathrm{~Hz}$ and $V_{\mathrm{AC}} 5 \mathrm{kV}$ with a wire of $D_{\text {out }}=0.8 \mathrm{~mm}$, as reported previously [1]. For wire with $D_{\text {out }}=0.8 \mathrm{~mm}$ (a), FSR decreased with AC frequency to $f_{\mathrm{AC}}=200(80) \mathrm{Hz}$ for $V_{\mathrm{AC}}=3(4) \mathrm{kV}$ and then increased, but decreased monotonically for $V_{\mathrm{AC}}=1,2$, and $5 \mathrm{kV}$. The spreading flames were extinguished at 1,000, 200, and $60 \mathrm{~Hz}$ when $V_{\mathrm{AC}}$ was 3,4 , and $5 \mathrm{kV}$, respectively; increasing $V_{\mathrm{AC}}$ thus reduced the 

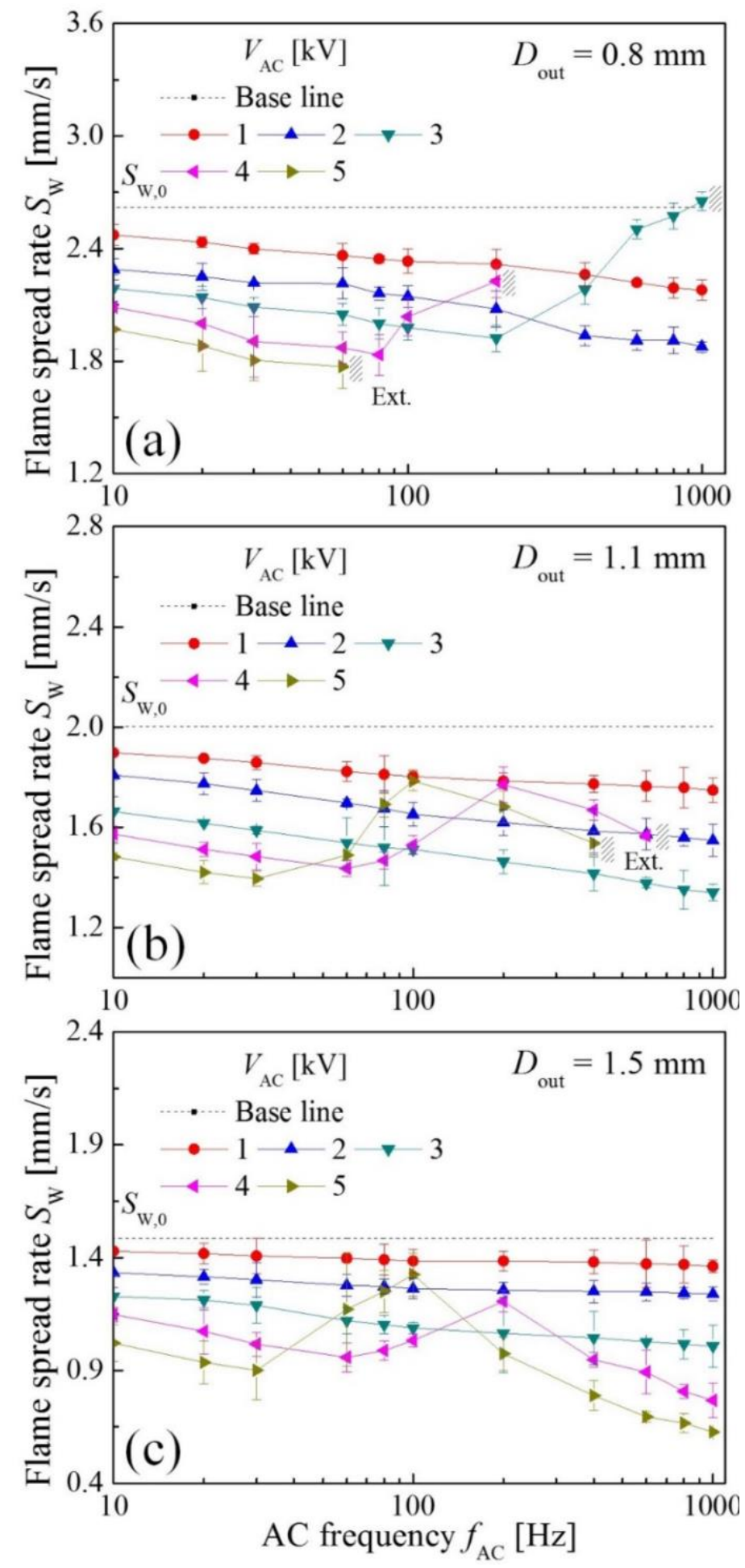

Figure 4. Flame spread rate against $\mathrm{AC}$ frequency at several voltages for wires of $D_{\text {out }}=0.8$ (a), 1.1 (b), and $1.5 \mathrm{~mm}$ (c).

critical frequency for flame extinction. For wires of $D_{\text {out }}=1.1$ and $1.5 \mathrm{~mm}(\mathrm{~b}, \mathrm{c}), \mathrm{FSR}$ decreased monotonically with increasing frequency at $V_{\mathrm{AC}}=1-3 \mathrm{kV}$, but decreased up to $60(30) \mathrm{Hz}$, 
increased up to $200(100) \mathrm{Hz}$ for $V_{\mathrm{AC}}=4(5) \mathrm{kV}$, and then decreased again as $f_{\mathrm{AC}}$ further increased. For wires of $D_{\text {out }}=1.1 \mathrm{~mm}$, flame extinction occurred at $600(400) \mathrm{Hz}$ at $4(5) \mathrm{kV}$, but the spreading flame of the $D_{\text {out }}=1.5 \mathrm{~mm}$ wire was not extinguished over our experimental frequency range. The details of flame extinction will be discussed in a later section. Based on the behavior of FSR by AC frequency, we defined three regimes: a decreasing FSR in regime I for a small $f_{\mathrm{AC}}$, an increasing FSR in regime II for an intermediate $f_{\mathrm{AC}}$, and a decreasing FSR once more in regime III for a large $f_{\mathrm{AC}}$. The details of such behaviors will be discussed later.

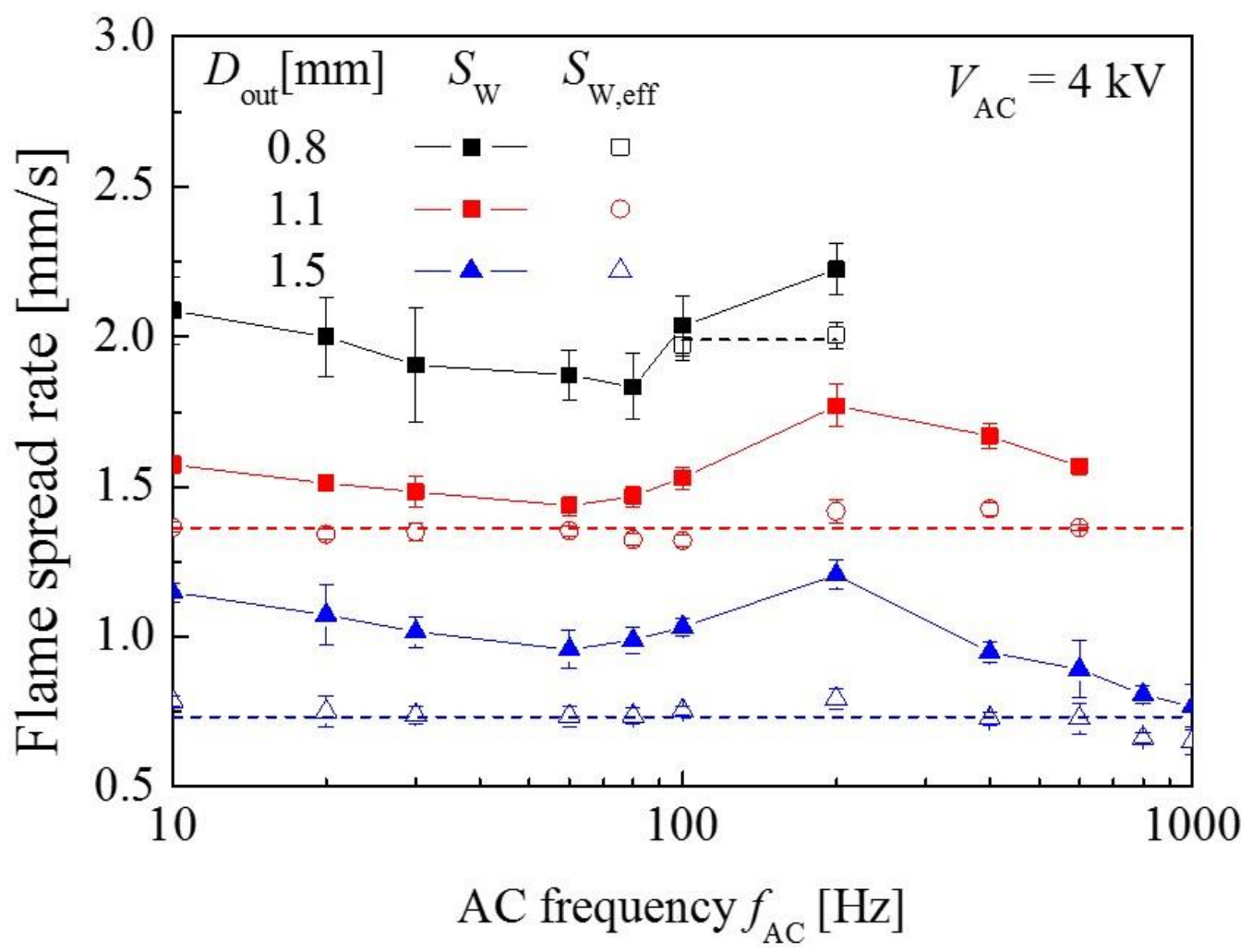

Figure 5. Effective flame spread rates against AC frequency for wires of different outer diameters at $V_{\mathrm{AC}}=4 \mathrm{kV}$. 

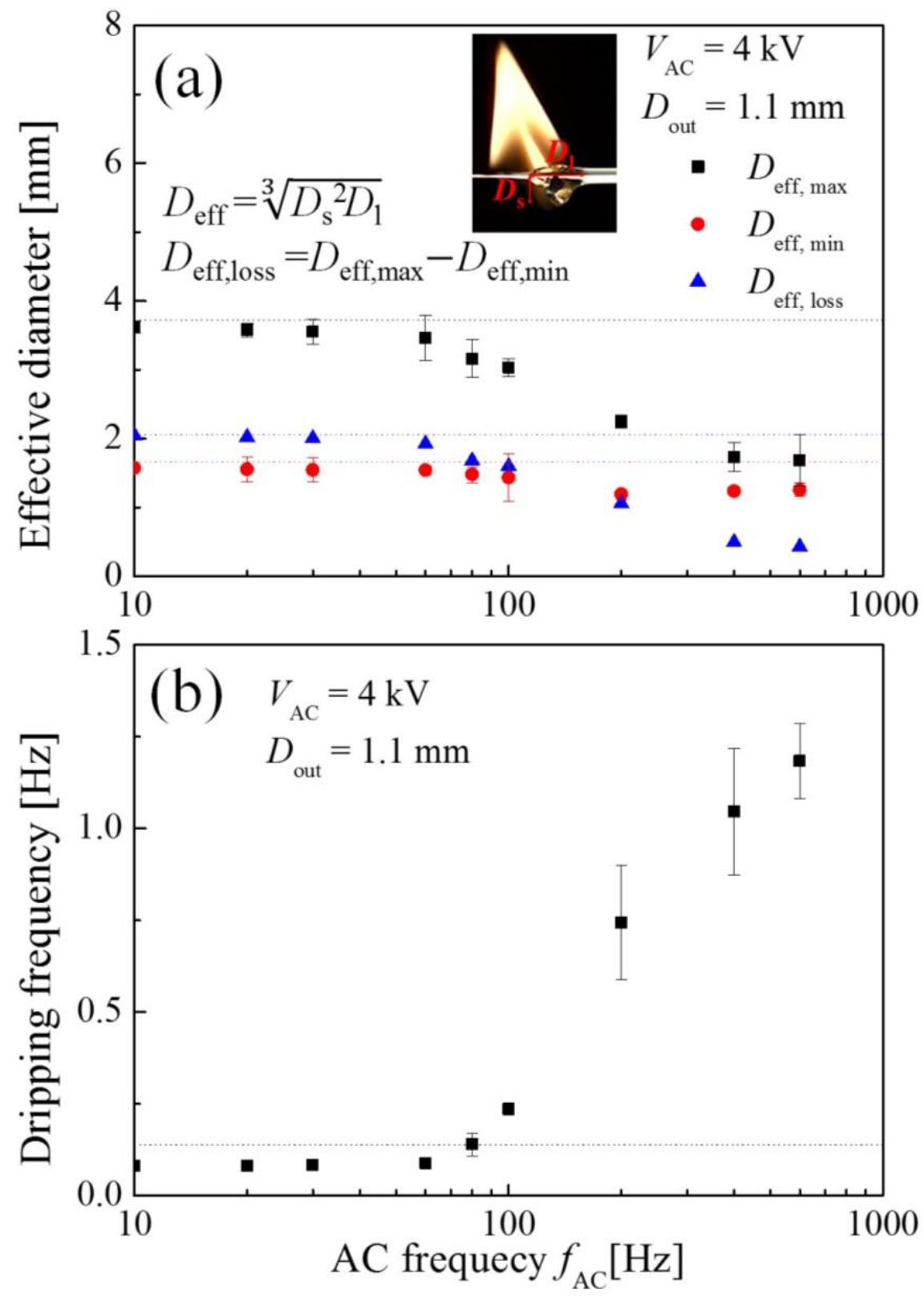

Figure 6. Quantification of molten $\mathrm{PE}$ dripping against $\mathrm{AC}$ frequency for $V_{\mathrm{AC}}=4 \mathrm{kV}$ and $D_{\text {out }}$ $=1.1 \mathrm{~mm}$.

Recall that molten PE drips to the ground in regimes II and III and a series of fine droplets is ejected from molten PE in regime III. This implies that the FSR does not appropriately represent the burning rate because of loss of molten PE. This changes the amounts of molten $\mathrm{PE}$ in the reaction zones, thereby influencing the instantaneous FSR even though the overall FSR is quasi-steady. 
As a flame spreads, the total mass consumption rate of PE, $\dot{m}_{\mathrm{PE}}$, can be expressed as the sum of the consumption rate via combustion, $\dot{m}_{\mathrm{C}}$, and that of mass loss $\dot{m}_{\mathrm{L}}$ caused by dripping of molten PE and the electrospray from the flame zone. Thus, an effective FSR that represents the burning rate, $S_{\mathrm{w}, \mathrm{eff}}$, can be defined as $S_{\mathrm{w}, \mathrm{eff}}=S_{\mathrm{w}}-\dot{m}_{\mathrm{L}} / \rho_{\mathrm{PE}} A[3]$, where $A$ is the cross-sectional area of PE. $\dot{m}_{\mathrm{L}}$ is determined by measuring the PE mass collecting on the ground from dripping of molten PE and the electrospray [3].

The spread rates $S_{\mathrm{w}, \text { eff }}$ and $S_{\mathrm{w}}$ against frequency are shown in Fig. 5 for the various wires at $V_{\mathrm{AC}}=4 \mathrm{kV}$; we present only instances where dripping and/or the electrospray were in play. Note that the FSR data for $f_{\mathrm{AC}}<100 \mathrm{~Hz}$ with $D_{\text {out }}=0.8 \mathrm{~mm}$ corresponds to cases without having dripping of molten PE. The results show that although $S_{\mathrm{w}}$ varied non-monotonically with $f_{\mathrm{AC}}$, the effective spread rates were very similar over the entire $\mathrm{AC}$ frequency range for all wires. This implies that the non-monotonic $S_{\mathrm{w}}$ behavior can be attributed to the mass loss of molten PE, emphasizing the important role played by such PE behavior.

To elucidate the behavior of molten PE dripping by AC frequency further, the effective diameter of molten PE ( $\left.D_{\text {eff }}\right)$ and the dripping frequency $\left(f_{\mathrm{d}}\right)$ at $V_{\mathrm{AC}}=4 \mathrm{kV}$ for a wire of $D_{\text {out }}=$ $1.1 \mathrm{~mm}$ are shown in Fig. 6. The dotted lines denote the baseline cases with no electric field. The molten PE was assumed to be ellipsoid in shape, of effective diameter $D_{\text {eff }}=\sqrt[3]{D_{\mathrm{S}}^{2} D_{\mathrm{l}}}$, where $D_{\mathrm{s}}$ and $D_{\mathrm{l}}$ are the short and long diameters (in the horizontal and vertical directions) of molten PE, as marked on the inset photograph in Fig. 6a. Here, $D_{\text {eff,max }}$ and $D_{\text {eff,min }}$ denote the effective diameters of molten PE suspended over an electrical wire before and after dripping. These data were taken in the range $109 \leq X \leq 128 \mathrm{~mm}$. The results (a) show that $D_{\text {eff,max }}$ and $D_{\text {eff,min }}$ (and thus $D_{\text {eff,loss }}=D_{\text {eff,max }}-D_{\text {eff,min }}$ ) decreased slowly up to $60 \mathrm{~Hz}$ and then decreased faster up to $600 \mathrm{~Hz}$ prior to flame extinction. The dripping frequency of molten PE by AC frequency (b) was almost constant up to $60 \mathrm{~Hz}$ and then increased appreciably. This implies 
that a large (small) amount of molten PE is lost at low (high) dripping frequencies at low (high) $\mathrm{AC}$ frequencies.

Note that the FSR increased with $\mathrm{AC}$ frequency in regime II (e.g., $60 \leq f_{\mathrm{AC}} \leq 200 \mathrm{~Hz}$ for $D_{\text {out }}=1.1 \mathrm{~mm}$ ) and then decreased in regime III (e.g., $200 \leq f_{\mathrm{AC}} \leq 600 \mathrm{~Hz}$ for $D_{\text {out }}=1.1 \mathrm{~mm}$ ) despite dripping of molten PE. The amount of residual molten PE (estimated from $D_{\text {eff,min }}$ ) by AC frequency decreased slightly for $60 \leq f_{\mathrm{AC}} \leq 200 \mathrm{~Hz}$ (Fig. 6a) but the flame size increased appreciably with AC frequency (see Fig. 2). This implies that a slight decrease in $D_{\text {eff,min }}$ increased the evaporation rate (and thereby the FSR) by reducing the heat capacity of molten PE. For $200 \leq f_{\mathrm{AC}} \leq 600 \mathrm{~Hz}$ for the $D_{\text {out }}=1.1 \mathrm{~mm}$ wire in Fig. $6 \mathrm{a}, D_{\text {eff,min }}$ increased slightly with AC frequency and the mass loss rate decreased appreciably, as did the flame size (see Fig. 2). In this situation, the flame reflects the large heat capacity of molten PE, reducing the evaporation rate and thereby the FSR, leading to flame extinction at $f_{\mathrm{AC}}>600 \mathrm{~Hz}$.

\subsection{Flame spread rate and flame size}

The overall burning behavior (or FSR) of wire flames is governed mainly by the diffusion flame surrounding the electrical wire [1-3]; flame size controls the overall burning behavior during heterogeneous combustion, as is also true of droplet flames. In such cases, the FSR reflects thermal balancing among conduction, convection, and radiation, as proposed earlier $[19,42]$. The effects include heat transfer from the flame to unburned and burnt wire, heat transfer to molten PE (via the wire) and the insulator, heat transfer to the ambient environment, and radiation. When one (or more) of these heat transfer characteristics is changed by an electric field, the balance of heat transfer will be modified. Then, the flame spread rate is adjusted to achieve re-balancing, e.g., in a situation of the leaning of a spreading flame toward the burnt wire side with larger electric field intensities compared with the unburned wire side 
FSRs over horizontal and inclined electrical wires of $D_{\text {out }}=0.8 \mathrm{~mm}$ under applied AC electric fields correlated reasonably with flame width [1-3]. In this regard, the FSR and flame width by varying $f_{\mathrm{AC}}$ are shown in Fig. 7 for $V_{\mathrm{AC}}=2(\mathrm{a}, \mathrm{b})$ and $4 \mathrm{kV}(\mathrm{c}, \mathrm{d})$. The flame width $(W)$ is defined as the length of wire between the portion burnt by the flame and the unburned region, as shown in the inset photograph in Fig. 7. The minimum, maximum, and average (arithmetic mean) flame width were taken in the range $109 \leq X \leq 178 \mathrm{~mm}$ for cases with dripping. The baseline cases (no electric field) are marked with dotted lines.
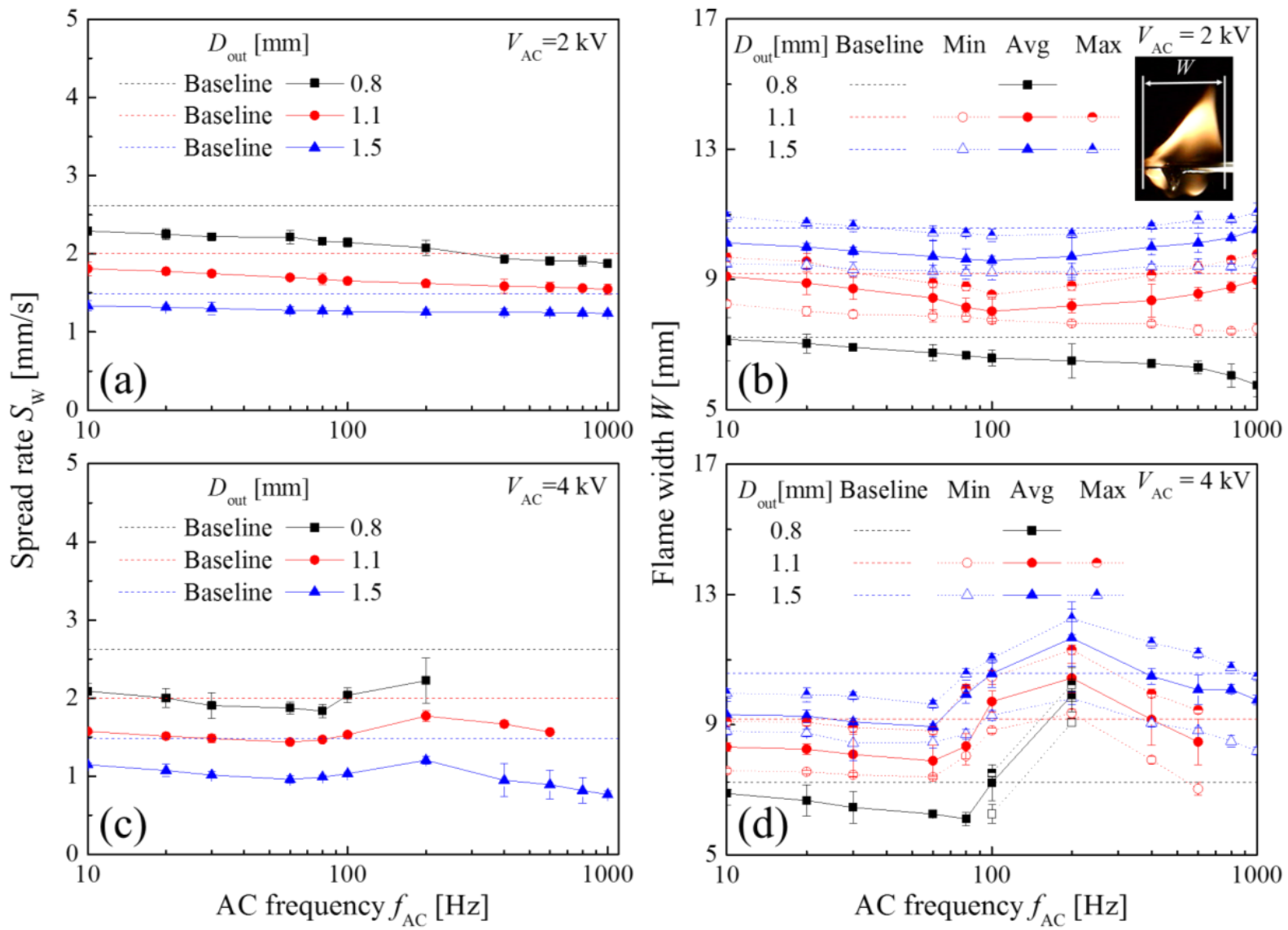

Figure 7. Relationships between the flame spread rate and flame width over the tested AC frequency range for wires of various outer diameters at $V_{\mathrm{AC}}=2 \mathrm{kV}(\mathrm{a}, \mathrm{b})$, and $4 \mathrm{kV}(\mathrm{c}, \mathrm{d})$.

For all wire diameters tested at $4 \mathrm{kV}$, and for the wire $D_{\text {out }}=0.8 \mathrm{~mm}$ tested at $2 \mathrm{kV}$, Fig. 7 shows that the flame widths qualitatively correlated well with the FSRs; a decrease in flame 
width caused a decrease in FSR.

However, for wires of $D_{\text {out }}=1.1$ and $1.5 \mathrm{~mm}$ under $2 \mathrm{kV}$, the FSR decreased monotonically by frequency whereas flame width decreased to $100 \mathrm{~Hz}$ and then increased. This can be attributed to the dynamic behaviors of molten PE (dripping, electrospray, and dielectrophoresis); all affect the FSRs of the $D_{\text {out }}=1.1$ and $1.5 \mathrm{~mm}$ wires, as will be elaborated later. Note that the effective FSR (combustion rate) was reasonably constant over the AC frequency range (Fig. 5). This indicates that the flame spread rate $S_{\mathrm{w}}$ corresponding to the melting rate of $\mathrm{PE}$ agreed reasonably well with flame width behavior.

\subsection{Behavior of molten PE}

Flame spread rates over an electrical wire under an electric field are influenced by many physical processes. When an electric field is applied to a wire, charged particles in the reaction zone are accelerated by the Lorentz force, enhancing the associated diffusion flux [1-3, 31]. The kinetic energy thus gained by charged particles may enhance the rate of chemical reaction. Accelerated ions transfer momentum to neutral particles, generating bulk flow (the ionic wind effect). Such interactions of electric fields with spreading flames appreciably modify flame shape and slant the flames, as discussed previously [1-3].

A flame edge enters into thermal and radical interactions with the heterogeneous surfaces of wires and insulators, resulting in local flame quenching. The flame edge then assumes the nature of a premixed flame via partial mixing through the quenching zone [1-3]. The flame propagation speed of a non-premixed edge flame [41, 43] and stabilization of a premixed Bunsen flame [40] are appreciably influenced by an electric field. Detailed quantification of the interaction of an electric field with a partially premixed flame edge near a wire remains difficult and will be the subject of our future work. Thus, identification of the fundamental 
physical processes in play is important for future quantification of such processes.

Interaction of molten PE with an applied electric field influences the FSR in a complex manner. As mentioned previously, soot deposition on the surfaces of molten PE and burnt wire modifies the various heat transfer modes, such as radiation from the flame to the wire and molten PE, heat conduction through the wire, convection heat transfer to molten PE from the wire, and conduction to the insulation material.

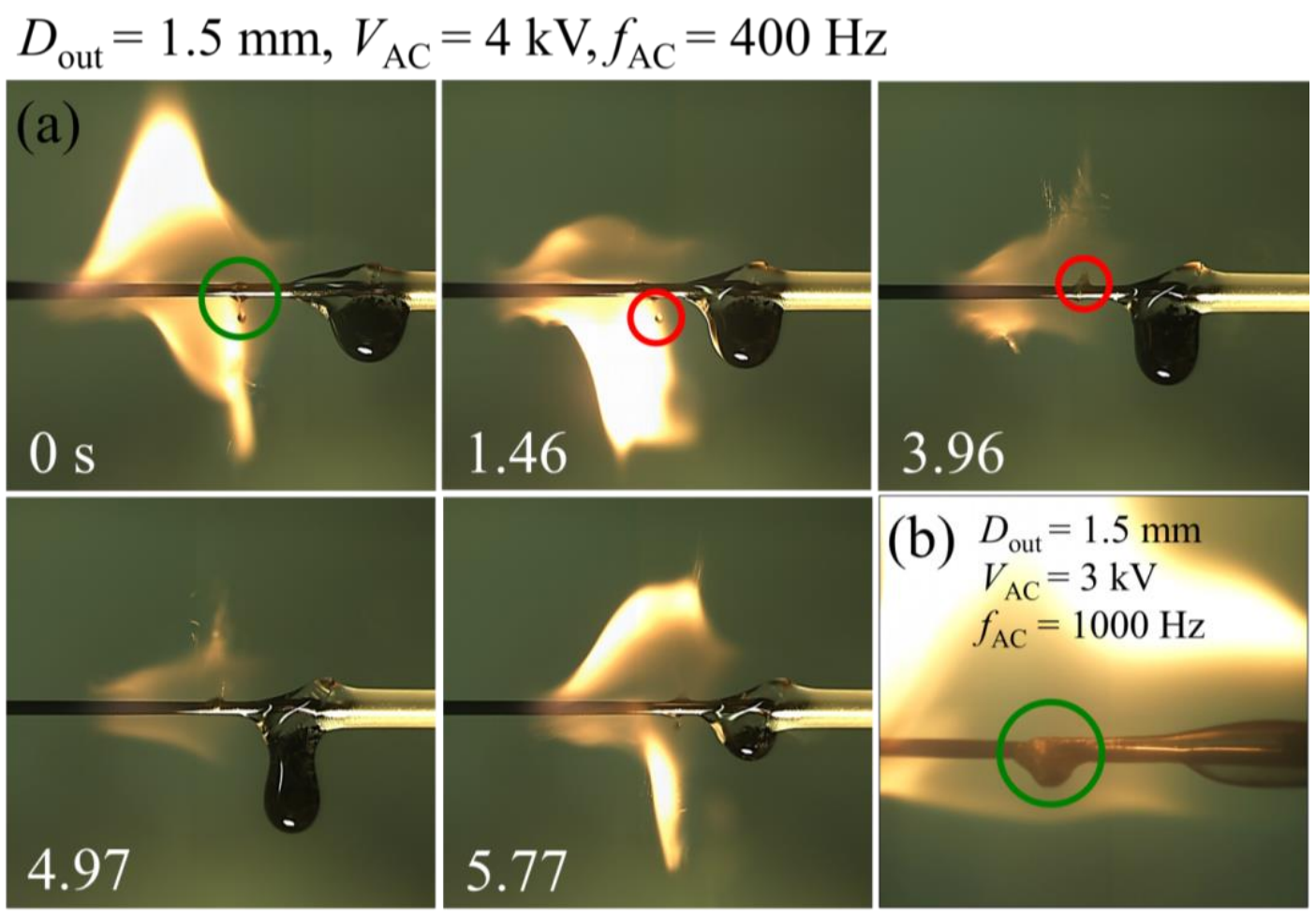

Figure 8. Close-up images showing the dynamic behaviors of molten $\mathrm{PE}$ in a spreading flame for a wire of $D_{\text {out }}=1.5 \mathrm{~mm}$ (a) at $V_{\mathrm{AC}}=4 \mathrm{kV}$ and $f_{\mathrm{AC}}=400 \mathrm{~Hz}$ exhibiting electrospray and dripping (see Supplementary Material 1) and (b) at $V_{\mathrm{AC}}=3 \mathrm{kV}$ and $f_{\mathrm{AC}}=1,000 \mathrm{~Hz}$ exhibiting di-electrophoresis.

When an electric field is applied to globular molten PE (containing both positive and negative ions) via the electrical wire, the positive ions drift toward the liquid surface and the negative ions away from the surface (for a positively charged wire). The accumulated positive ions on the surface can become concentrated in the outermost skin layer. Subsequently, the 
liquid surface is drawn out to form a liquid Taylor cone. Under a sufficiently high electric field, small droplets can be ejected from the surface of the molten PE in the form of an electrospray [44-47], as discussed in detail previously for inclined wire with $D_{\text {out }}=0.8 \mathrm{~mm}$ [3].

Joule heating also enhances melting and evaporation of insulator material. However, this effect would be expected to be minor, because the applied electric power is very small compared to the heat generated by a wire flame [2]. The dripping of molten PE and the electrospray tend to reduce the FSR because of mass loss of molten PE [2, 3].

In the present study, globular molten PE was observed to detach from the main body of the molten PE and subsequently to migrate in the shape of droplets toward burnt wires; this will later be shown to reflect di-electrophoresis. This increases the surface area of molten PE and the flame width, enhancing the evaporation rate, thereby increasing the FSR.

The behavior of molten PE is further visualized in Fig. 8 via high-speed close-up imaging at $V_{\mathrm{AC}}=4 \mathrm{kV}$ and $f_{\mathrm{AC}}=400 \mathrm{~Hz}$ for a $D_{\text {out }}=1.5 \mathrm{~mm}$ wire (a) (see Supplementary Material 1 for movies) and at $V_{\mathrm{AC}}=3 \mathrm{kV}$ and $f_{\mathrm{AC}}=1,000 \mathrm{~Hz}$ for the same wire (b). The results in (a) show that the principal molten PE region grew gradually. The black color of the molten PE indicates that it was filled with fine soot particles. Soon after 4.97 s, molten PE dripped onto the ground; a significant loss of molten PE is evident at $5.77 \mathrm{~s}$.

Notably, globular molten PE detached from the main body of molten PE and moved toward the burnt wire (as marked by green circles) at $0 \mathrm{~s}$ in both Figs. $8 \mathrm{a}$ and $8 \mathrm{~b}$, attributable to dielectrophoresis. A series of fine droplets was then emitted (in the direction normal to the burnt wire) from the detached, globular molten PE (as marked in red circles in Fig. 8a) in the vertically downward (0 and $1.46 \mathrm{~s})$ and upward (3.96 and $4.97 \mathrm{~s})$ directions; the flame became 


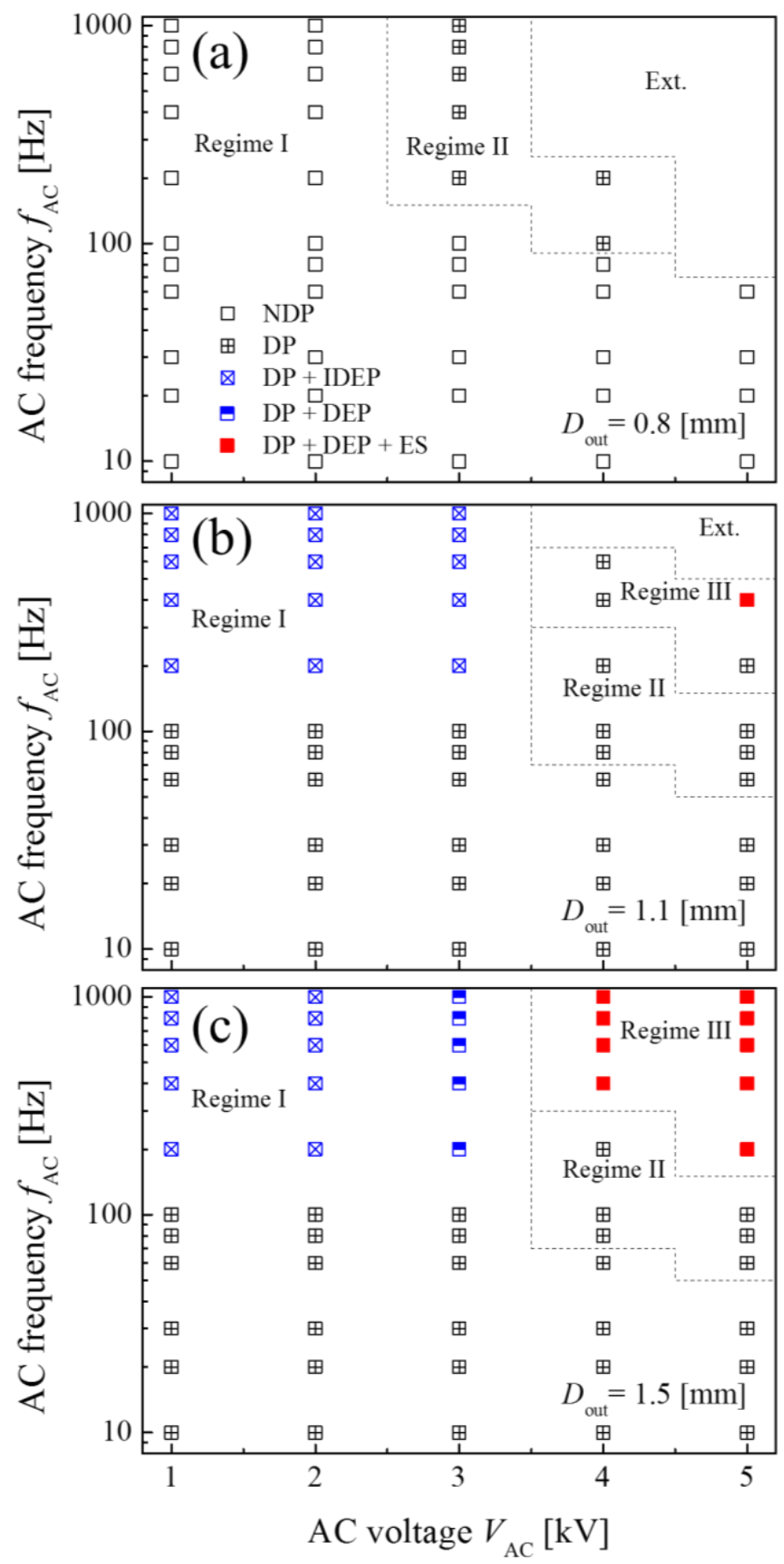

Figure 9. Regime diagram based on the dynamic behaviors of molten PE under various applied AC electric fields for (a) $D_{\text {out }}=0.8$, (b) 1.1 , and (c) $1.5 \mathrm{~mm}$ (NP, no dripping; DP, dripping; ES, electrospraying; DEP, di-electrophoresis; IDEP, intermittent DEP).

elongated vertically. This was attributed to the electrospray observed previously in inclined wires [3]. Both the di-electrophoresis and electrospray were continuously repeated during 
flame spread. The details of electrospray and dripping of molten PE have been explained previously $[2,3]$. Thus, we focus on the details of the di-electrophoresis phenomenon later.

Figure 9 shows a regime diagram based on the dynamic behaviors of molten PE in terms of applied AC voltage and frequency for wires of $D_{\text {out }}=0.8$ (a), 1.1 (b), and $1.5 \mathrm{~mm}$ (c). Here, NDP denotes no-dripping of molten PE; DP dripping, ESP electrospray, DEP di-electrophoresis, and IDEP indicates intermittent DEP. During the DEP in the present study, globules of molten PE continuously detached from the main body of molten PE and moved to the burnt wire rendering the flame width near-constant. During IDEP, such dynamic behavior occurred occasionally, such that the flame width enlarged (shrank) during DEP occurrence (nonoccurrence).

Recall that regimes I, II, and III were defined based on a decrease, increase, and a decrease once more in FSR with increasing AC frequency, respectively. For a wire with $D_{\text {out }}=0.8 \mathrm{~mm}$, only DP was observed at high voltages and frequencies. The flame size decreased with frequency (Fig. 2) in the absence of molten PE DP during regime I. Thus, the FSR reduction was attributable to a reduction in flame size caused by inclination of the spreading flame toward the burnt wire, caused by the ionic wind effect of the uneven electric field [1-3]. In regime II, molten PE DP occurred at high voltages and frequencies in the absence of the ESP and DEP, and the flame size increased appreciably. Thus, the increase in FSR was attributable predominantly to increasing flame width (Fig. 2) potentially caused by the effect of the electric field on edge flames, enhancing the evaporation rate (and thus the FSR) by reducing the heat capacity of molten PE (via the decrease in $D_{\text {eff,min }}$; Fig. 6). When the mass loss of molten PE (fuel loss) became excessive, the flame size decreased and flame extinction occurred [1].

For the $D_{\text {out }}=1.1 \mathrm{~mm}$ wire, DP of molten PE occurred at all tested voltages and frequencies. IDEP also occurred at $200 \leq f_{\mathrm{AC}} \leq 1,000 \mathrm{~Hz}$ and $1 \leq V_{\mathrm{AC}} \leq 3 \mathrm{kV}$. Under these conditions (e.g., 
$200 \leq f_{\mathrm{AC}} \leq 1,000 \mathrm{~Hz}$ and $V_{\mathrm{AC}}=2 \mathrm{kV}$ ), flame width increased and FSR decreased slightly. Such reduction in FSR with increasing frequency (Fig. 6) was attributable principally to mass loss of molten PE by DP. The DP frequency of molten PE increased with $V_{\mathrm{AC}}$ and $f_{\mathrm{AC}}$ [2]. IDEP was replaced in regime II with appreciable DP, implying that IDEP was suppressed by DP. The correlation between FSR and flame width was restored; both FSR and flame width increased simultaneously (Fig. 7). In regime III, given the flame size reduction caused by DP of molten PE, both the FSR and flame width decreased once more, causing flame extinction on an increase in frequency. DEP and ES occurred simultaneously with DP only at $f_{\mathrm{AC}}=400 \mathrm{~Hz}$ and $V_{\mathrm{AC}}=5 \mathrm{kV}$ in regime III.

For the $D_{\text {out }}=1.5 \mathrm{~mm}$ wire, the behavior of molten PE in regime I was similar to that of the $D_{\text {out }}=1.1 \mathrm{~mm}$ wire except at $3 \mathrm{kV}$, where DEP occurred instead of IDEP. In regime II featuring appreciable DP of molten PE (but no DEP or ESP), the correlation of FSR and flame width was restored; both FSR and flame width increased with frequency. When the voltage increased from $3 \mathrm{kV}$ (where DP and DEP occurred together) to $4 \mathrm{kV}$ at $200 \mathrm{~Hz}$, DEP disappeared, confirming that DEP was again suppressed by DP. When regime II changed to regime III on a further increase in $f_{\mathrm{AC}}, \mathrm{DP}$ of molten $\mathrm{PE}$, DEP, and the ESP all occurred simultaneously (Supplementary Material 1 and Fig. 8) in all cases. In regime III, the main body of molten PE grew over time and dripped when the size of the molten PE region was sufficiently large. When molten PE globules detached and moved toward the burnt wire (DEP), fine droplets were subsequently ejected from the globules (ESP). As the effects of mass fuel loss caused by DP and the ESP reduced the flame more than the increase mediated by DEP, FSR decreased with frequency in regime III as shown in Fig. 4.

\subsection{Flame spread rate correlations}


Table 1. Electric field intensities $\left(|d E / d r|_{D_{\text {out }}}\right.$ values) at the outer surfaces of $\mathrm{PE}$ at various $V_{\mathrm{DC}}$ values, calculated using FEMM v-4.2 software for wires of different outer diameters.

\begin{tabular}{|r|c|c|c|}
\hline $\begin{array}{c}|d E / d r|_{\mathrm{D}_{\text {out }}} \\
{\left[\mathrm{kV} / \mathrm{mm}^{2}\right]}\end{array}$ & $\mathrm{D}_{\text {out }}[\mathrm{mm}]=0.8$ & 1.1 & 1.5 \\
\hline$V_{\mathrm{DC}}[\mathrm{kV}]=1$ & 7.15 & 4.94 & 2.56 \\
\hline 2 & 14.29 & 9.89 & 5.13 \\
\hline 3 & 22.28 & 15.19 & 8.09 \\
\hline 4 & 28.59 & 19.77 & 10.25 \\
\hline 5 & 35.74 & 24.72 & 12.82 \\
\hline
\end{tabular}

We here attempt to correlate FSR in each regime (based on molten PE behavior). The experimental parameters were wire diameter $\left(D_{\mathrm{c}}\right)$, wire outer diameter $\left(D_{\mathrm{out}}\right)$, AC voltage $\left(V_{\mathrm{AC}}\right)$, and frequency $\left(f_{\mathrm{AC}}\right)$. It has been shown previously $[38,48-50]$ that electric field intensity $(E)$ plays a crucial role for various flame responses. Since $E$ is time varying with $A C$, we have separately parameterized the AC effect through the magnitude of electric field intensity by assuming applying DC and the AC frequency. The radial electric field intensity from the metal core to the outer surface of the PE and beyond depends on the PE thickness. For a spreading flame, the flame edge at the unburned wire in contact with the insulation material would be expected to play an important role; we thus selected the electric field intensity at the outer surface of the PE, $|\mathrm{d} E / \mathrm{d} r|$ Dout, as the representative electric field intensity. This was calculated using FEMM v-4.2 software [51] assuming an axisymmetric infinite wire with insulation material, and the results are listed in Table 1 by varying DC voltage and wire outer diameter. The wire core and outer diameters influence heat conduction through the core and insulation material, respectively, and the amount of molten PE available during flame spread. Here, we 
have selected the ratio $\left(D_{\mathrm{out}} / D_{\mathrm{c}}\right)$ as a non-dimensional geometric factor in seeking correlations. Thus, the relative FSR of $S_{\mathrm{w}} / S_{\mathrm{w}, 0}$ was correlated as a function of $f\left(f_{\mathrm{AC}},|\mathrm{d} E / \mathrm{d} r|\right.$ Dout, $\left.D_{\mathrm{out}} / D_{\mathrm{c}}\right)$, depending on observed NDP, DP, DEP, IDEP, and ES, and their combinations.

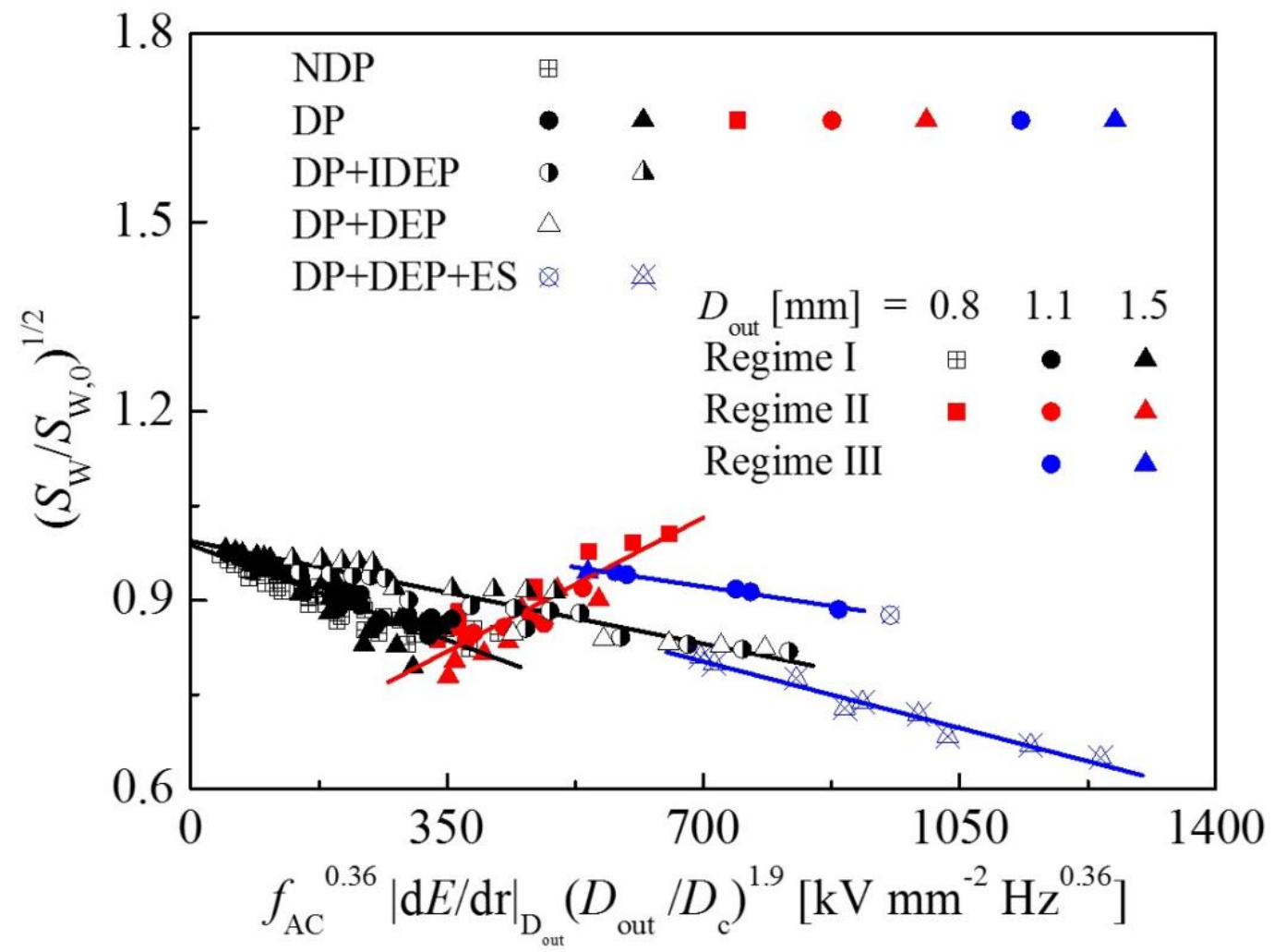

Figure 10. Flame spread rates in various $A C$ electric fields by reference to molten $P E$ behaviors (NP, no dripping; DP, dripping; ES, electrospray; DEP, di-electrophoresis; IDEP, intermittent DEP).

The results are shown in Fig. 10 in terms of $\left(S_{\mathrm{w}} / S_{\mathrm{w}, 0}\right)^{1 / 2}=A \times f\left(f_{\mathrm{AC}},|\mathrm{d} E / \mathrm{d} r|\right.$ Dout, $\left.D_{\text {out }} / D_{\mathrm{c}}\right)+B$ with $f=f_{\mathrm{AC}}^{0.36} \times|d E / d r|_{D_{\text {out }}} \times\left(D_{\text {out }} / D_{c}\right)^{1.9}\left[\mathrm{~Hz}^{0.36} \times \mathrm{kV} / \mathrm{mm}^{2}\right]$ for each regime through a leastsquare analysis in determining the exponents. Note that the exponent 1.9 for $\left(D_{\text {out }} / D_{\mathrm{c}}\right)(\mathrm{close}$ to 2) implies that area effects of wire and insulation material are in play, associated with the conductive surface and the amount of PE per unit length. In regime I, where FSR decreased with AC frequency, examples involving either DP (black solid symbols) or NDP (black plus- 
marked hollow symbols) were associated with the constants $A=-4.30 \times 10^{-4}$ and $B=0.99$ with a correlation coefficient $R=0.90$. Those with both DP and IDEP (half-solid black symbols) or both DP and DEP (black hollow triangular symbols) were associated with the constants $A=$ $-2.33 \times 10^{-4}$ and $\mathrm{B}=0.99$ with $R=0.93$. In regime II, where FSR increased with AC frequency and only DP was observed (red solid symbols), the constants were $A=6.07 \times 10^{-4}$ and $B=0.61$ with $R=0.88$. In regime III, where FSR again decreased with AC frequency, examples exhibiting only DP (blue solid symbols) were associated with the constants $A=$ $-1.76 \times 10^{-4}$ and $B=1.04$ with $R=0.99$; and those exhibiting all of DP, ESP, and DEP (blue cross-marked hollow symbols) with constants $A=-3.01 \times 10^{-4}$ and $B=1.01$ and $R=0.99$.

Note that the correlations were appreciably influenced by the dynamic behaviors of molten PE, especially in regimes I and III. On simultaneous occurrence of DP and DEP (IDEP) in regime I, the characteristic curve deviated (FSR increased) from that associated with DP only because of the increase in flame size caused by DEP (IDEP). When DP occurred together with the ESP and DEP in regime III, the normalized FSR also fell from that associated with only DP because of additional mass loss of molten PE via the ESP. These findings emphasize the important roles played by the dynamic behaviors of molten PE (DEP and/or IDEP) on FSR. As the DP and ESP phenomena were observed previously and have been discussed in detail [1-3], we will focus on the DEP phenomenon below; this is the first such observation in wire fire studies.

\subsection{Di-electrophoresis phenomenon}

The phenomenon characterized by the relative motion of a medium (liquid or solid) resulting from polarization forces generated by an inhomogeneous electric field is termed the DEP phenomenon [52]. DEP does not require an ionized medium, rather asymmetric induction and 


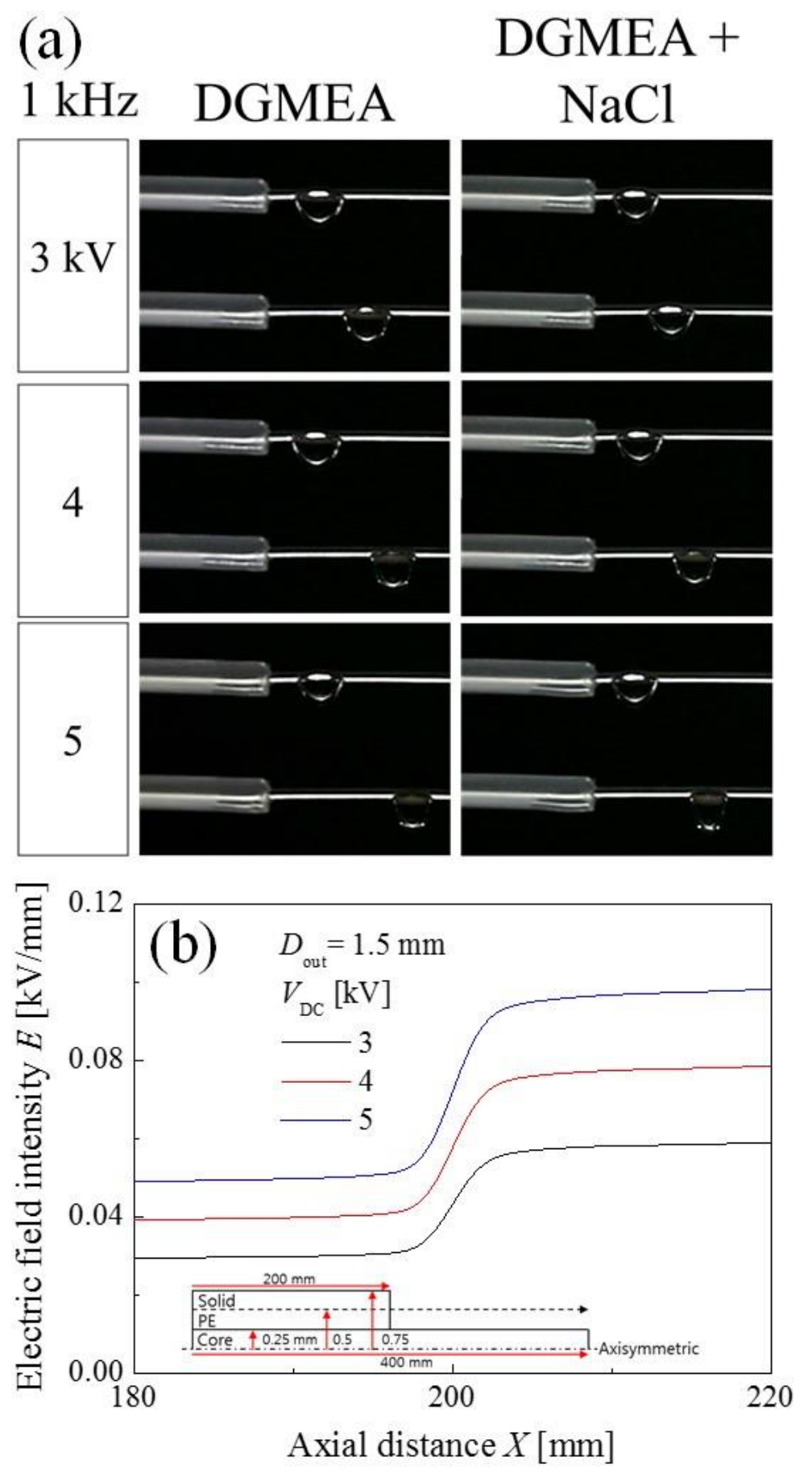

Figure 11. Effects of $\mathrm{AC}$ voltages on the movements of dipoles $\left(\mathrm{C}_{8} \mathrm{H}_{16} \mathrm{O}_{4}\right)$ and ionized $\left(99.9 \%\right.$ vol $\mathrm{C}_{8} \mathrm{H}_{16} \mathrm{O}_{4}+0.1 \%$ vol $\left.\mathrm{NaCl}\right)$ liquid droplets via di-electrophoresis (a); and axial

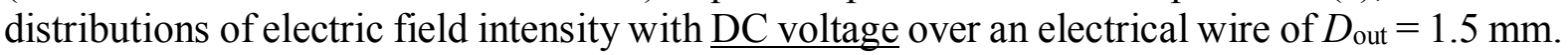

attraction of displacement charges within the medium. The unequal field forces acting on permanent or induced dipoles cause them to move toward the region of higher electric field intensity. Liquid DEP, deployed at microscopic scales on top of hydrophobic surfaces, affords 
novel automated manipulation of small amounts of aqueous polar samples for microfluidic applications and development of laboratory-on-a-chip devices [53-57]. The technology has also been used to capture cells in the biological and biomedical fields [58-62]. The effect of applied voltage on DEP was visualized at $f_{\mathrm{AC}}=1 \mathrm{kHz}$ using liquid droplets of $\mathrm{C}_{8} \mathrm{H}_{16} \mathrm{O}_{4}$ (diethylene glycol monoethyl ether acetate, DGMEA), which is dipolar, and 99.9\% (volume) DGMEA $+0.1 \%$ (volume) $\mathrm{NaCl}$ (which is ionized), by suspending $1.0-\mu \mathrm{L}$ amounts of the materials on bare wires near the ends of the insulated wire (upper photographs) as shown in Figure 11a (see Supplementary Material 2 for movies). When an electric field was applied, the liquid droplets moved toward the bare wire side (lower photographs); DEP was in play. Increasing $V_{\mathrm{AC}}$ increased the distance moved by both dipolar and ionized liquid droplets.

As an uneven electric field intensity is required for DEP development, variations in electric field intensity over an electrical wire to which a DC voltage was applied were explored using FEMM v-4.2 software [49] during a step change in the insulation material, as depicted in Figure $11 \mathrm{~b}$ for $D_{\text {out }}=1.5 \mathrm{~mm}$. The electric field intensity was plotted at a radial distance $0.075 \mathrm{~mm}$ from the core center (the center of the insulation material).

The results show that the electric field intensity increased appreciably across the boundary of the insulation material ( $X=200 \mathrm{~mm}$ in this case), toward the bare wire side. This implies that a liquid droplet (either dipolar or ionized) would move toward the larger electric field intensity of the bare wire, as shown in Fig. 11a. Increasing the applied voltage increases the difference between the electric field intensities on the sides of the bare and insulated wires, causing liquid droplets to move further via DEP.

A previous study revealed the functional dependence of the extent of droplet movement via DEP as follows [55]. Consider two parallel plane electrodes (oriented vertically) with a spacing of $S$ immersed in a pool of dielectric liquid of permittivity $\alpha$. When the dielectric liquid is 
covered by a gas of permittivity $\alpha_{0}$, and a voltage $(V)$ is applied to the electrodes, the static distance is proportional to $\left(\alpha-\alpha_{0}\right)(V / S)^{2}$ [56].

This finding was used to estimate the distance moved by a PE droplet when flame spread over an electrical wire. The distance $L$ moved by molten PE over a wire under an applied AC electric field is thus assumed to be functionally dependent on $\left(\alpha_{\mathrm{PE}}-\alpha_{\mathrm{air}}\right)\left(E_{\mathrm{u}}-E_{\mathrm{b}}\right)^{2}$, where $\alpha_{\mathrm{PE}}$ and $\alpha_{\mathrm{air}}$ are the permittivities of PE and air, respectively. $E_{\mathrm{u}}$ and $E_{\mathrm{b}}$ are the electric field intensities on the PE surface at the unburnt and burnt sides of the wire (derived using FEMM v-4.2 software assuming applying DC for the magnitude).

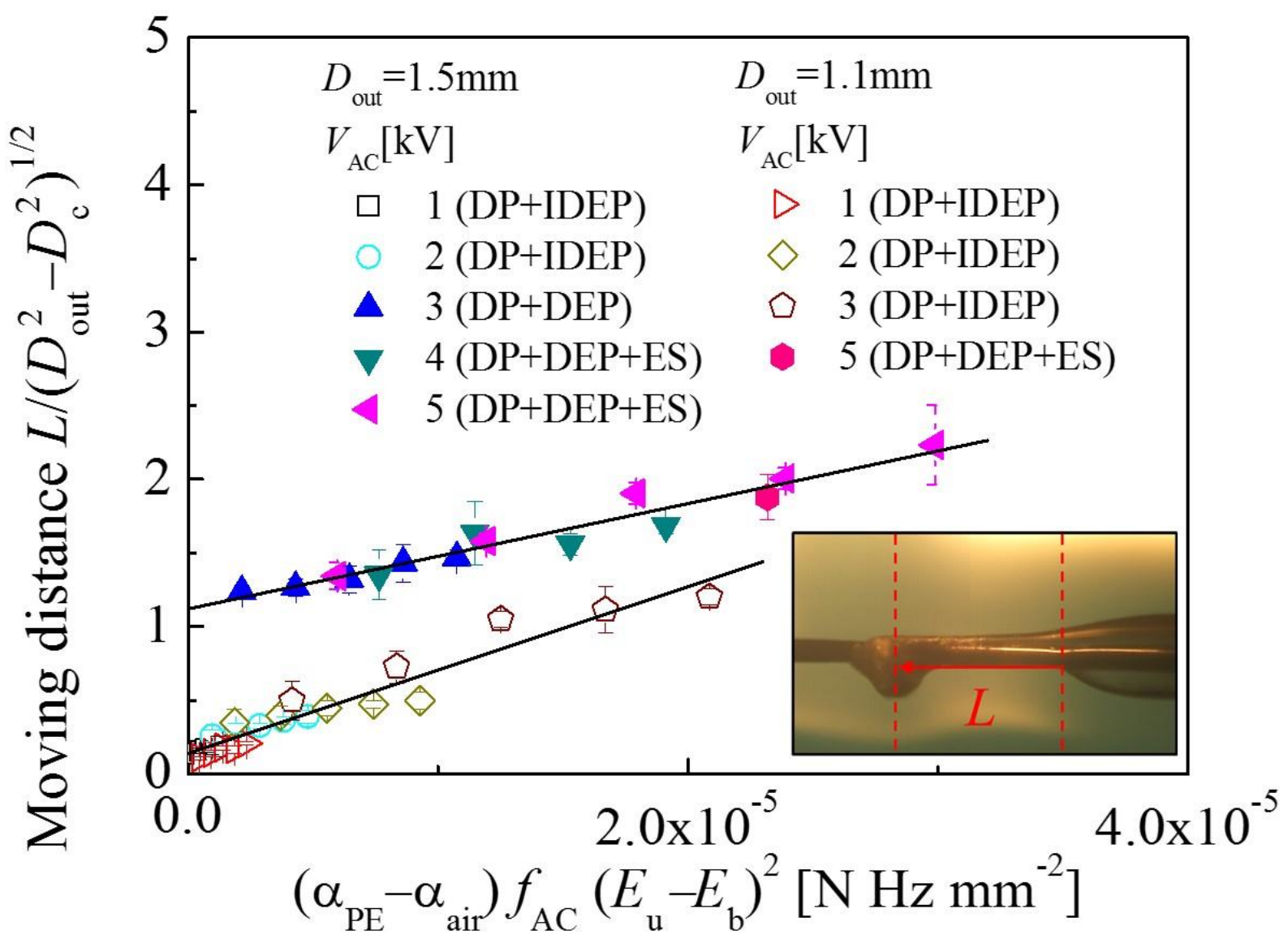

Figure 12. The distances moved by molten PE via di-electrophoresis, and related physical parameters.

When representing the distance moved by molten PE detached from the main body, we considered the $\mathrm{AC}$ frequency, which represents the rate of change of the electric field. Therefore, 
we tested the relationship described by $L \propto\left(\alpha_{\mathrm{PE}}-\alpha_{\mathrm{air}}\right) f_{\mathrm{AC}}\left(E_{\mathrm{b}}-E_{\mathrm{u}}\right)^{2}$. Note that a parameter $\left(D_{\text {out }}{ }^{2}-D_{\mathrm{c}}{ }^{2}\right)$ is also considered which could represent available molten PE during flame spread related to the cross-sectional area of PE insulation. The results are shown in Fig. 12 for wire of $D_{\text {out }}=1.1$ and $1.5 \mathrm{~mm}$. Here, $\alpha_{\mathrm{PE}}$ and $\alpha_{\text {air }}$ were $2.04 \times 10^{-11}$ and $8.86 \times 10^{-12} \mathrm{~N} / \mathrm{V}^{2}[63]$, respectively.

Excellent correlations between the measured distance moved by molten PE globule and the expression: $L /\left(D_{\text {out }}^{2}-D_{\mathrm{c}}^{2}\right)^{1 / 2}[\mathrm{~mm}]=A\left(\alpha_{\mathrm{PE}}-\alpha_{\mathrm{air}}\right) f_{\mathrm{AC}}\left(E_{\mathrm{b}}-E_{\mathrm{u}}\right)^{2}+B\left[\mathrm{~N} \cdot \mathrm{Hz} \cdot \mathrm{mm}^{-2}\right]$ was apparent where $A=5.64 \times 10^{4}\left(3.57 \times 10^{4}\right)$ and $B=0.14(1.12)$ for IDEP (DEP); both the $R$ values was 0.97 (describing $f_{\mathrm{AC}}$ in $[\mathrm{Hz}], E$ in $[\mathrm{V} / \mathrm{mm}]$, and $\alpha$ in $\left[\mathrm{N} / \mathrm{V}^{2}\right]$ ), irrespective of the simultaneous (or not) occurrence of DP, DEP, and the ES. Here, $\left(E_{\mathrm{b}}-E_{\mathrm{u}}\right)$ represents the driving force of DEP, related to the gradient of electric field intensity. Although not shown, we also tested the maximum gradient employing the $E$ values at $X=200 \mathrm{~mm}$ (Fig. 11b); these afforded correlations as satisfactory as those yielded employing the $\left(E_{\mathrm{b}}-E_{\mathrm{u}}\right)$ approach. The results also show that increasing the cross-sectional area of PE insulation (thereby increasing available volume of molten PE) reduces the moving distance of molten PE from the main body of molten. Such an analysis could be identified well in the present experimental ranges of 1-5 $\mathrm{kV}$ and $0-1000 \mathrm{~Hz}$, based on the quasi-steady behavior of di-electrophoresis with frequency, as shown in Fig. 12.

\subsection{Flame extinction}

Wire flames were extinguished when the voltage and frequency became excessive, as shown in Fig. 2 for wires of $D_{\text {out }}=0.8$ and $1.1 \mathrm{~mm}$. Figure 13 shows the functional dependence of extinction frequency on voltage divided by wire outer diameter (associated with electric field intensity). The extinction frequency decreased with increasing (decreasing) $V_{\mathrm{AC}}\left(D_{\text {out }}\right)$, best 
fitted by $\log \left(f_{\mathrm{AC}, \text { ext }}\right)[\mathrm{Hz}]=-0.39 \times V_{\mathrm{AC}}[\mathrm{kV}] / D_{\text {out }}[\mathrm{mm}]+4.24$ with $\mathrm{R}=0.94$. Note that $D_{\text {out }}$ includes the effect of insulation thickness on flame extinction, since the core diameter is fixed. Increasing the outer wire diameter implies more fuel available and thereby showing higher resistance to flame extinction, resulting in the increase in extinction frequency. Thus, high voltage, a small outer wire diameter, and high AC frequency promoted flame extinction. Note this correlation is phenomenological one and a detailed physical parameterization including the effect of $D_{\mathrm{c}}$ should be a future study.

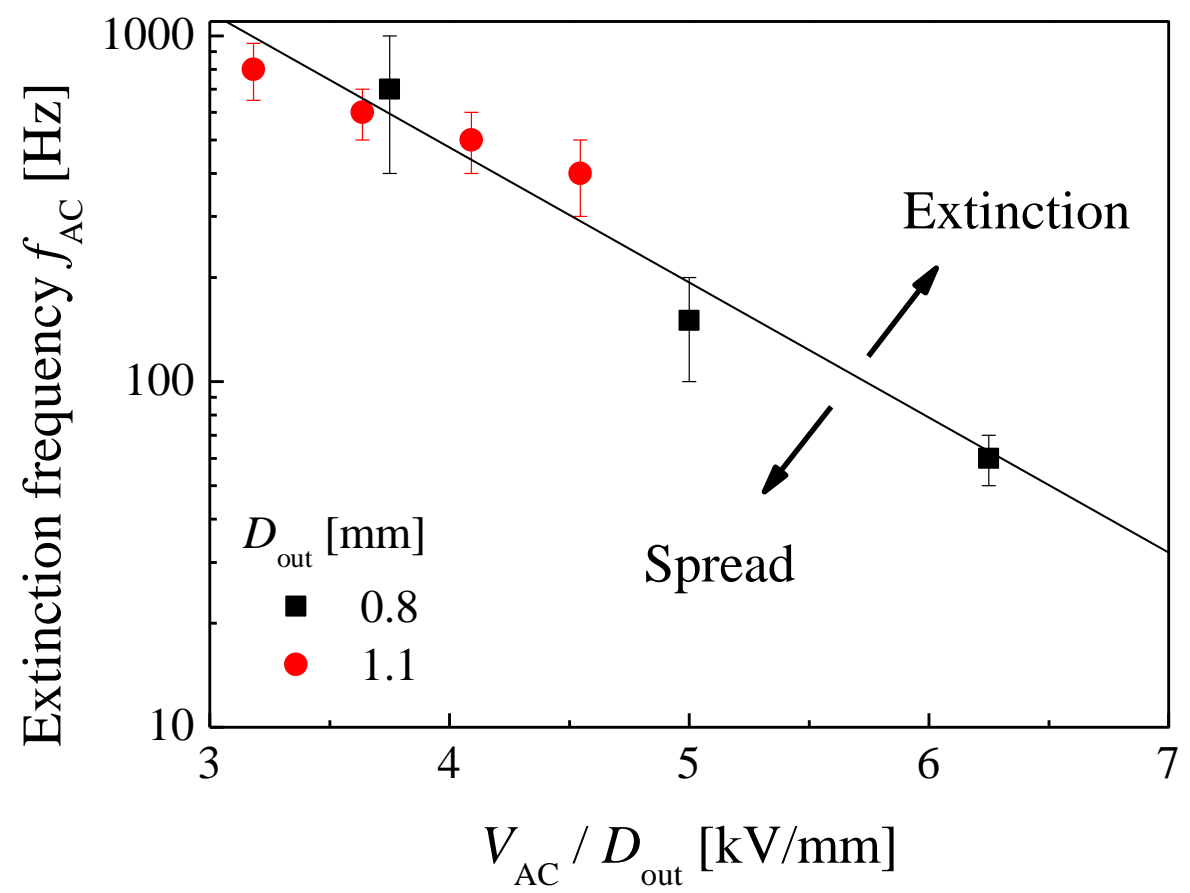

Figure 13. The extinction frequencies reveal their functional dependencies on applied voltage and wire diameter.

Figure 14 exhibits sequential images showing the processes leading to extinction in spreading flames for $D_{\text {out }}=0.8 \mathrm{~mm}$ at (a) $5 \mathrm{kV}$ and $80 \mathrm{~Hz}$ and (b) $4 \mathrm{kV}$ and $300 \mathrm{~Hz}$. Flame extinction occurred via two routes similar to the previous observation [1]: (1) flame spread rate decreases with both voltage and frequency such that, as shown in Fig. 14a, excessive reduction of flame size (thereby insufficient heat transfer) yields deficient evaporation of fuel, resulting 
in flame extinction due to lack of fuel (regime I) as shown in Fig. 14b and (2) appreciable amount of soot is deposited to the surface of molten PE, yielding the absorption of radiative heat to molten PE, subsequently reducing the surface tension of molten PE, and thereby leading to the dripping of molten PE onto the ground and thereby flame extinction due to excessive mass loss of molten PE (regimes II and III) as shown in Fig. 14b.

$$
D_{\text {out }}=0.8 \mathrm{~mm}
$$

(a) $V_{\mathrm{AC}}=5 \mathrm{kV}, f_{\mathrm{AC}}=90 \mathrm{~Hz}$
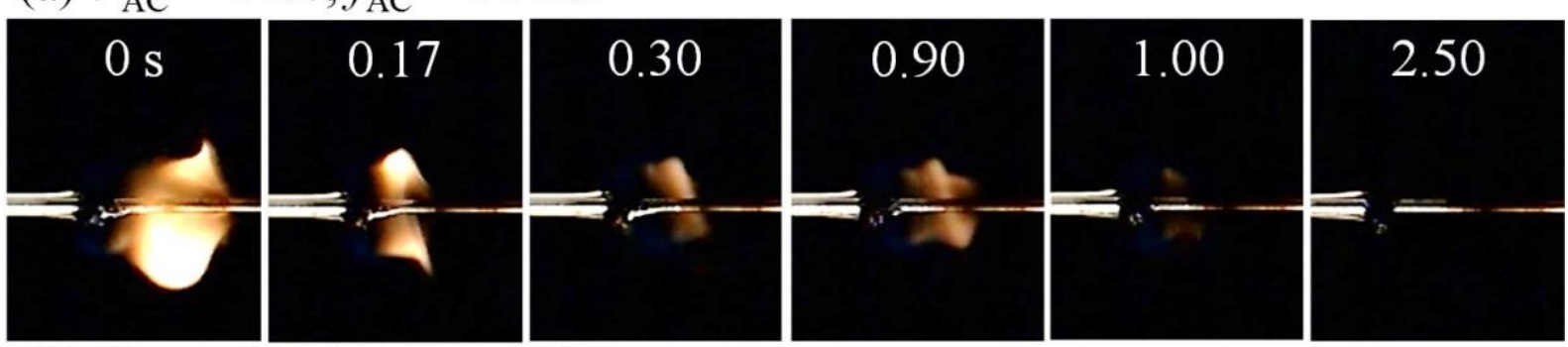

(b) $V_{\mathrm{AC}}=4 \mathrm{kV}, f_{\mathrm{AC}}=300 \mathrm{~Hz}$
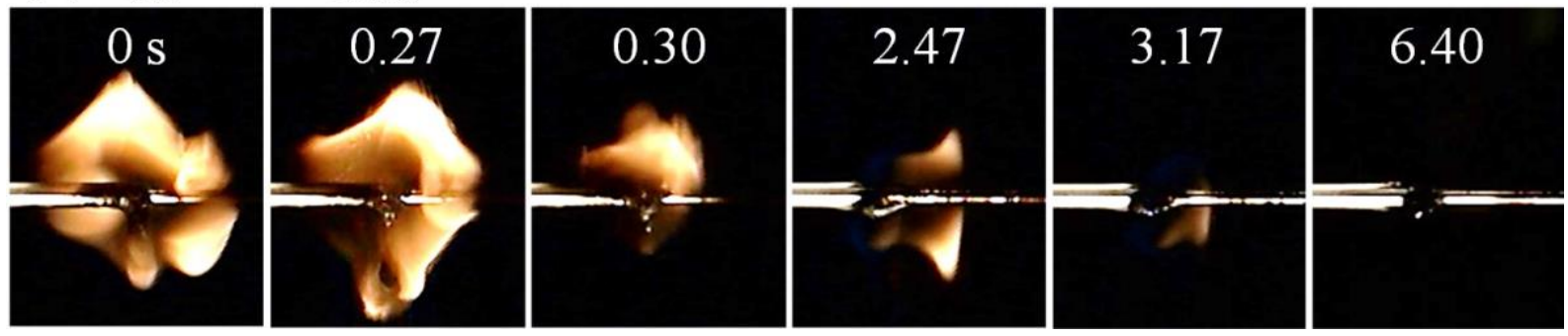

Figure 14. Sequential images showing the extinguishing processes in spreading flames for a wire of $D_{\text {out }}=0.8 \mathrm{~mm}$ at (a) $5 \mathrm{kV}$ and $90 \mathrm{~Hz}$ and (b) $4 \mathrm{kV}$ and $300 \mathrm{~Hz}$.

We found that when an AC electric field was applied, the FSR generally decreased compared to the baseline value (no electric field), mitigating flame spread. However, as described previously [3], small electrospray droplet flames could propagate flaming to neighboring wire regions. Also, molten dripping material promotes PE flaming, exposing neighboring combustible materials to ignition. In space, dripping would be absent (there is no gravity); flame spread would increase greatly from the baseline value. Thus, it would be interesting to explore the electric field effects on wire flames under microgravity conditions. 


\section{Concluding remarks}

The effects of an AC electric field and wire diameter on flame spread over PE-insulated electrical wires were investigated in the $f_{\mathrm{AC}}$ range $0-1,000 \mathrm{~Hz}, V_{\mathrm{AC}}$ range $0-5 \mathrm{kV}$, and $D_{\text {out }}$ range $0.8-1.5 \mathrm{~mm}$. In baseline cases (no electric field), the FSR (flame width) decreased (increased) with wire outer diameter. Application of an electric field significantly influenced both flame size and the FSR. The FSR behavior was categorized into three regimes; decreasing, increasing, and decreasing once more with increasing $f_{\mathrm{AC}}$. The FSR $\left(S_{\mathrm{w}} / S_{\mathrm{w}, 0}\right)^{1 / 2}$ value exhibited functional dependency on $f_{\mathrm{AC}},|d E / d r|_{D_{\text {out }}}$, and $D_{\text {out }} / D_{\mathrm{c}}$.

At low voltages and high frequencies, for wires of large $D_{\text {out }}$ values of 1.1 and $1.5 \mathrm{~mm}$, the FSR and flame width exhibited opposite tendencies, emphasizing the important roles played by the dynamic behaviors of molten PE. At high frequencies, droplets detached from the main bodies of molten PE and moved toward the burnt wires. The distance moved was proportional to the square of the axial difference in electric field intensities between points on the outermost surfaces of the molten PE. The associated flames were resistant to extinction, because the phenomenon described above increased the FSR by increasing flame width. This phenomenon was attributed to di-electrophoresis, here observed for the first time in the context of wire fire research. When DEP is evident at high $\mathrm{AC}$ voltages and frequencies for a wire with $D_{\text {out }}=1.5$ mm, multiple small droplets are continuously ejected from the moving droplets (the ESP); the main body of molten PE grows to drip onto the ground. These complicated dynamic phenomena, including mass loss of molten PE (via ESP), and the increase in flame width caused by DEP, significantly influence the FSR. DEP occurs when molten PE experiences a non-uniform electric field intensity over an electrical wire, and is associated with the electric field applied and the electrical properties of the materials in play. Considering the importance 
of these dynamic behaviors of molten insulation material in flame spread, further studies with other core and insulation materials are needed in the future.

Flame extinction occurred via two routes: via appreciable reduction in flame size and excessive dripping of molten PE. The extinction frequency decreased with increasing (decreasing) $V_{\mathrm{AC}}\left(D_{\mathrm{out}}\right)$, and was characterized by functional dependence of the $f_{\mathrm{AC}}$ on $V_{\mathrm{AC}} / D_{\text {out }}$

\section{Acknowledgements}

This research was supported by the SGER Program through the National Research Foundation of Korea (NRF) funded by the Ministry of Education, Science, and Technology (2017-2018). SHC \& MSC were supported by King Abdullah University of Science and Technology.

\section{References}

[1] M.K. Kim, S.H. Chung, O. Fujita, Effect of AC electric fields on flame spread over electrical wire, Proc. Combust. Inst. 33 (2011) 1145-1151.

[2] S.J. Lim, M.K. Kim, J. Park, O. Fujita, S.H. Chung, Flame spread over electrical wire with AC electric fields: Internal circulation, fuel vapor-jet, spread rate acceleration, and molten insulator dripping, Combust. Flame 162(4) (2015) 1167-1175.

[3] S.J. Lim, S.H. Park, J. Park, O. Fujita, S.I. Keel, S.H. Chung, Flame spread over inclined electrical wires with AC electric fields, Combust. Flame 185 (2017) 82-92.

[4] https://timesofindia.indiatimes.com/india/Fire-in-cables-led-to-accident-in-submarineINS-Sindhuratna-Navy-says/articleshow/31336637.cms

[5] R. Friedman, Fire safety in spacecraft, Fire Mater. 20(5) (1996) 235-243.

[6] F. Jia, M. Patel, E. Galea, A. Grandison, J. Ewer, CFD fire simulation of the Swissair flight 111 in-flight fire- Part II: Fire spread within the simulated area, Aeronaut. J. 110 (2006) 303-314.

[7] O. Keski-Rahkonen, J. Mangs, Electrical ignition sources in nuclear power plants: Statistical modeling and experimental studies, Nuclear Engineering and Design 213(2) (2002) 209-221.

[8] A. Matala, S. Hostikka, Probabilistic simulation of cable performance and water based protection in cable tunnel fires, Nuclear Engineering and Design 241(12) (2011) 52635274.

[9] L. Li, X. Huang, K. Bi, X. Liu, An enhanced fire hazard assessment model and validation experiments for vertical cable trays, Nuclear Engineering and Design 301 (2016) 32-38. 
[10] Cable response to live fire (CAROLFIRE) Volume 1: Test description and analysis of circuit response data, NURGE/CR-6931, SAND2007-600/V1.

[11] Cable response to live fire (CAROLFIRE) Volume 2: Cable fire response data for fire model improvement, NURGE/CR-6931, SAND2007-600/V2.

[12] Cable response to live fire (CAROLFIRE) Volume 3: Thermally induced electrical failure (THIEF) model, NURGE/CR-6931, NISTIR7472.

[13] Y. Takeno, O. Fujita, N. Shigeta, Y. Nakamura, H. Ito, Ignition limits of short-term overloaded electric wires in microgravity, Proc. Combust. Inst. 34 (2013) 2665-2673.

[14] X. Huang, Y. Nakamura, F. Williams, Ignition-to-spread transition of externally heated electrical wire, Proc. Combust. Inst. 34 (2013) 2505-2512.

[15] K. Shimizu, M. Kikuchi, N. Hashimoto, O. Fujita, A numerical and experimental study of the ignition of insulated electrical wire with long-term excess current supply under microgravity, Proc. Combust. Inst. 36 (2017) 3063-3071.

[16] A.F. Osorio, K. Mizutani, C. Fernandez-Pello, O. Fujita, Microgravity flammability limits of ETFE insulated wires exposed to external radiation, Proc. Combust. Inst. 35 (2015) 2683-2689.

[17] M. Kikuchi, O. Fujita, K. Ito, A. Sato, T. Sakuraya, Experimental study on flame spread over wire insulation in microgravity, Proc. Combust. Inst. 27 (1998) 2507-2514.

[18] O. Fujita, K. Nishizawa, K. Ito, Effect of low external flow on flame spread over polyethylene-insulated wire in microgravity, Proc. Combust. Inst. 29 (2002) 2545-2552.

[19] A. Umemura, M. Uchida, T. Hirata, J. Sato, Physical model analysis of flame spreading along an electrical wire in microgravity, Proc. Combust. Inst. 29 (2002) 2535-2543.

[20] Y. Nakamura, N. Yoshimura, K. Ito, K. Azumaya, O. Fujita, Flame spread over electric wire in sub-atmospheric pressure, Proc. Combust. Inst. 32 (2009) 2559-2566.

[21] S. Takahashi, H. Takeuchi, H. Ito, Y. Nakamura, O. Fujita, Study on unsteady molten insulation volume change during flame spreading over wire insulation in microgravity, Proc. Combust. Inst. 34 (2013) 2657-2664.

[22] L. Hu, Y. Zhang, K. Yoshioka, H. Izumo, O. Fujita, Flame spread over electric wire with high thermal conductivity metal core at different inclinations, Proc. Combust. Inst. 35 (2015) 2607-2614.

[23] L. Hu, Y. Lu, K. Yoshioka, Y. Zhang, C. Fernandez-Pello, S. H. Chung, O. Fujita, Limiting oxygene concentration for extinction of upward spreading flames over inclined thin polyethylene-insulated $\mathrm{NiCr}$ wires with opposed-flow under normal- and micro-gravity, Proc. Combust. Inst. 36 (2017) 3045-3053.

[24] Y. Lu, X. Huang, L. Hu, C. Fernandez-Pello, The interaction between fuel inclination and horizontal wind: experimental study using thin wire, to be published in Proc. Combust. Inst. 37 (2018), https://doi.org/10.1016/i.proci.2018.05.131.

[25] R. Friedman, Fire safety in extraterrestrial environments, NASA TM-1998-207417, 1998.

[26] R. Friedman, Fire safety in the low-gravity spacecraft environment, NASA TM-1999209285, 1999.

[27] A.G. Ruff, L.D. Urban, K.M. King, A research plan for fire prevention, detection, and suppression in crewed exploration systems, AIAA 2005-0341, 2005.

[28] A.G. Ruff, L. D. Urban, Technology development for fire safety in exploration spacecraft and habitats, AIAA 2007-350, 2007.

[29] NASA STD 6001B, Flammability, offgassing, and compatibility requirements and test procedures, 2011.

[30] NASA NHB 8060.1C, Flammability, odor, offgassing, and compatibility requirements and test procedures for materials in environments that support combustion, 1991. 
[31] J. Lawton, F. J. Weinberg, Electrical Aspect of Combustion, Clarendon Press, Oxford, 1969.

[32] X. Zhao, J. M. Guerrero, X. Wu, Review of aircraft electric power systems and architectures, Proc. IEEE Int. Energy Conf. (2014) 949-953.

[33] M. Goller, K. Rogalla, HV Design of Vacuum-insulated Power Supplies for Space Applications, IEEE Trans. Electrical Insulation 28(4) (1993) 667-680.

[34] R. Lanoie, H.P. Mercure, Influence of forest fire on power line insulation, $6^{\text {th }}$ Int. Symp. High Voltage Eng. (1989) paper 30.06.

[35] W.L. Vosloo, J.P. Holzhausen, A.C. Britten, Research into the detection of fires under high voltage lines, 7th Int. Symp. High Voltage Eng. (1991) paper 41.12.

[36] Y. Xiong, M.S. Cha, S.H Chung, Ac electric field induced vortex in laminar coflow diffusion flames, Proc. Combust. Inst. 35 (2015) 3513-3520.

[37] O. Fujita, K. Ito, T. Chida, S. Nagai, Y. Takeshita, Determination of magnetic field effects on a jet diffusion flame in a microgravity environment, Proc. Combust. Int. 27 (1998) 25732578.

[38] D.G. Park, S.H. Chung, M.S. Cha, Dynamic responses of counterflow nonpremixed flames to AC electric field, Combust. Flame 198 (2018) 240-248.

[39] Y. Xiong, D.G. Park, M.S. Cha, S.H. Chung, Effect of buoyancy on dynamic response of coflow diffusion flame under low-frequency alternating current, Combust. Sci. Tech. 190 (2018) 1832-1849.

[40] M.K. Kim, S.H. Chung, H.H. Kim, Effect of AC electric fields on the stabilization of premixed Bunsen flames, Proc. Combust. Inst. 33 (2011) 1137-1144.

[41] S.K. Ryu, Y.K. Kim, M.K. Kim, S.H. Won, S.H. Chung, Observation of multi-scale oscillation of laminar lifted flames with low-frequency AC electric fields, Combust. Flame 157 (2010) 25-32.

[42] Y. Nakamura, N. Yoshimura, T. Matsumura, H. Ito, Opposed-wind effect on flame spread of electric wire in sub-atmospheric pressure, J. Thermal Sci. Tech. 3 (2008) 430-441.

[43] S.H. Won, S.K. Ryu, M.K. Kim, M.S. Cha, S.H. Chung, Effect of electric fields on the propagation speed of tribrachial flames in coflow jets, Combust. Flame 152 (2008) 496506.

[44] L. Rayleigh, On the equilibrium of liquid conducting masses charged with electricity, Phil. Mag. 14(87) (1882) 184-186.

[45] A. Gomez, K. Tang, Charge and fission of droplets in electrostatic sprays, Phys. Fluids 6(1) (1994) 404-414.

[46] G. Taylor, Disintegration of water droplets in an electric field, Proc. Royal Soc. London A: Mathematical, Physical \& Engineering Sciences 291 (1965) 145-158.

[47] S.P. Lin, G. Roberts, Waves in a viscous liquid curtain, J. Fluid Mech. 112 (1981) 443458.

[48] S.H. Won, M.S. Cha, C.S. Park, S.H. Chung, Effect of electric fields on reattachment and propagation speed of tribrachial flames in laminar coflow jets, Proc. Combust. Inst. 31 (2007) 963-970.

[49] Y. Xiong, D.G. Park, B.J. Lee, S.H. Chung, M.S. Cha, DC field response of onedimensional flames using an ionized layer model, Combust. Flame 163 (2016) 317-325.

[50] D.G. Park, S.H. Chung, M.S. Cha, Bidirectional ionic wind in nonpremixed counterflow flames with DC electric fields, Combust. Flame 168 (2016) 138-146.

[51] Finite Element Method Magnetics v-4.2. http://www.femm.info/wiki/

[52] H.A. Pohl, Motion and precipitation of suspensoids in divergent electric fields, J. Appl. Phys. 22(7) (1951) 869-871. 
[53] T. B. Jones, M. P. Perry, J. R. Melcher, Electrostatics and the lab on a chip, Science 174 (1971) 1232-1233.

[54] K. V. I. S. Kaler, R. Prakash, D. Chugh, Droplet microfluidics for chip-based diagnostics, Biomicrofluidics 4 (2010) 022805:1-17.

[55] T. B. Jones, Liquid dielectrophoresis on the microscale, J. Electrostatics 51-52 (2001) 290-299.

[56] T. B. Jones, M. Gunji, M. Washizu, M. J. Feldman, Dielectrophoretic liquid actuation and nanodroplet formation, J Appl Phys 89 (2001) 1441-1448.

[57] R. Ahmed, T.B. Jones, Dispensing picoliter droplets on substrates using dielectrophoresis, J. Electrostatics 64 (2006) 543-549.

[58] P.R.C. Gascoyne, Y. Huang, R. Pethig, J. Vykoukal, F. Becker, Dielectrophoretic segregation of different human cell types on microscope slides, Meas. Sci. Technol. 3 (1992) 439-445.

[59] T. P. Hunt, D. Issadore, R. M. Westervelt, Integrated circuit/microfluidic chip to programmably trap and move cells and droplets with dielectrophoresis, Lab. Chip 8(1) (2007) 81-87.

[60] C.H. Kua, Y.C. Lam, L. Rodriguez, C. Yang, K. Youcef-Toumi, Dynamic cell fractionation and transportation using moving dielectrophoresis, Anal. Chem. 79 (2007) 6975-6987.

[61] H. Moncada-Hernandez, J.L. Baylon-Cardiel, V.H. Perez-Gonzalez, B. H. LapizcoEncinas, Insulator-based dielectrophoresis of microorganisms: theoretical and experimental results, Electrophoresis 32 (2011) 2502-2511.

[62] L. M. Broche, N. Bhadal, M. P. Lewis, S. Porter, M. P. Hughes, F. H. Labeed, Early detection of oral cancer-Is dielectrophoresis the answer?, Oral Oncology 43 (2007) 199203.

[63] L.G. Hector, H.L. Schultz, The dielectric constant of air at radiofrequencies, J. Appl. Phys. 7 (4) (1936) 133-136. 